\title{
WestVirginiaUniversity
}

THE RESEARCH REPOSITORY @ WVU

Graduate Theses, Dissertations, and Problem Reports

2006

\section{Theory of mind and the assessment of suggestibility in preschoolers}

Aryn C. Karpinski

West Virginia University

Follow this and additional works at: https://researchrepository.wvu.edu/etd

\section{Recommended Citation}

Karpinski, Aryn C., "Theory of mind and the assessment of suggestibility in preschoolers" (2006).

Graduate Theses, Dissertations, and Problem Reports. 4239.

https://researchrepository.wvu.edu/etd/4239

This Thesis is protected by copyright and/or related rights. It has been brought to you by the The Research Repository @ WVU with permission from the rights-holder(s). You are free to use this Thesis in any way that is permitted by the copyright and related rights legislation that applies to your use. For other uses you must obtain permission from the rights-holder(s) directly, unless additional rights are indicated by a Creative Commons license in the record and/ or on the work itself. This Thesis has been accepted for inclusion in WVU Graduate Theses, Dissertations, and Problem Reports collection by an authorized administrator of The Research Repository @ WVU. For more information, please contact researchrepository@mail.wvu.edu. 
Theory of Mind and the Assessment of Suggestibility in Preschoolers

Aryn C. Karpinski

\begin{abstract}
Thesis submitted to the Eberly College of Arts and Sciences at West Virginia University in partial fulfillment of the requirements

for the degree of
\end{abstract} Master of Science
in
Life-Span Developmental Psychology

Matthew H. Scullin, Ph.D., Chair Katherine H. Karraker, Ph.D. William J. Fremouw, Ph.D. Department of Psychology Morgantown, West Virginia
2006

Keywords: Suggestibility, Theory of Mind, VSSC, Event Memory Copyright 2006 Aryn C. Karpinski 


\begin{abstract}
Theory of Mind and the Assessment of Suggestibility in Preschoolers
\end{abstract}

\title{
Aryn C. Karpinski
}

Researchers have been examining the relation between theory of mind and suggestibility with mixed results. Recently, researchers have suggested that theory of mind is not a dichotomous construct, but instead develops in a sequence (Wellman \& Liu, 2004). This view, when combined with an examination suggestibility, may clarify the relation. The purpose of this study was to validate the Video Suggestibility Scale for Children (VSSC; Scullin \& Ceci, 2001) and a theory of mind scale as predictors of suggestibility in an interview about an experienced and a non-experienced event. Ninety-one preschoolers, ages 3 to 5 years old, completed the 3week study. Results indicated that the theory of mind scale aided strongly in predicting suggestibility about an experienced event in addition to the VSSC. Awareness of factors related to suggestibility is important because this can alert professionals to be cautious in their interviews with children who are "highly suggestible." 


\section{Dedication}

I would like to dedicate this research project to my family, especially my parents, who have made my entire academic career possible. I would also like to dedicate this to my graduate and undergraduate educators who saw my potential and encouraged me to pursue my goals. 


\section{Acknowledgements}

I would like to thank everyone who has helped and supported me throughout my academic career.

First, I would like to thank Dr. Matthew H. Scullin for his ideas, immense wealth of knowledge, and guidance that I needed to finish this project with great success. I would also like to thank the Developmental faculty for their continued guidance and advice during the process: Dr. JoNell Strough, Dr. Katherine Karraker, Dr. Jennifer Margrett, Dr. Stan Cohen, Dr. Julie Patrick, and Dr. Hawley Montgomery-Downs. Thank you to my committee for their advice and assistance with this project: Dr. William Fremouw and Dr. Katherine Karraker.

Second, I would like to thank my many, many research assistants who helped collect and code the data: Neely Snead, Shannon Wilson, Lynnsey Carrell, Rebecca Highland, Evan Shumaker, Jennifer Reese, Lauren King, Laura Manuel, Jaisal Pragani, and Kaitlyn Cobb.

Third, I would like to thank my wonderful magician, lab partner, and friend, Sam Insana. I would also like to thank all of my friends here at WVU for their support. Thanks especially to Nicky Elliott, Tara Neely, Rebecca Ryan, Marion Young, Dr. Karri Bonner Verno, and Wes for their special attention, guidance, and encouragement. Thank you for believing in me.

Finally, I wish to acknowledge the alumni who donated to the Psychology Department's Alumni Fund, without which I would not have had the supplies necessary to carry out this project. 


\section{Table of Contents}

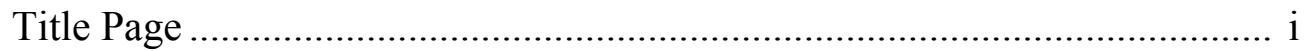

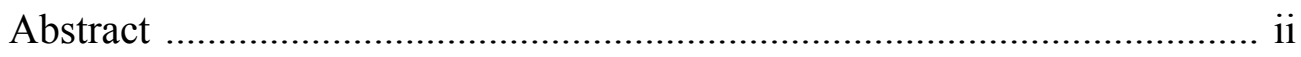

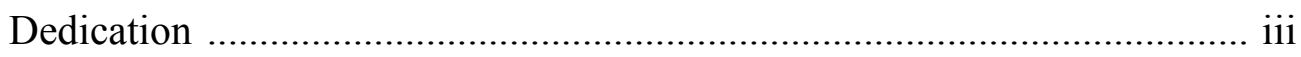

Acknowledgements ............................................................................. iv

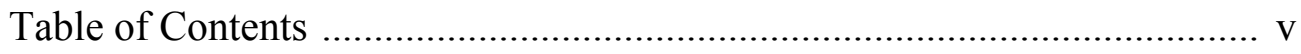

List of Tables ................................................................................. vii

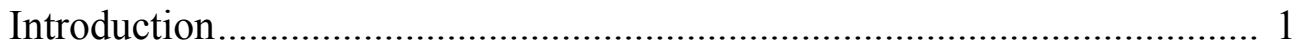

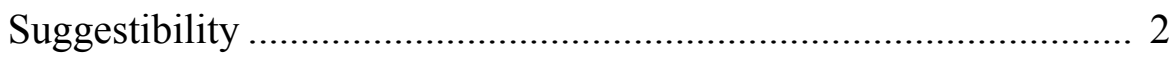

Children's Vulnerability to Suggestion ........................................ 3

Assessment of Suggestibility in Children ....................................... 4

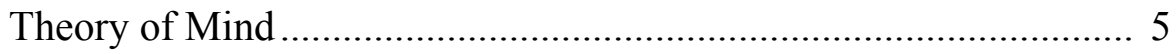

Theory of Mind and Suggestibility ............................................ 7

Rationale and Statement of the Problem ........................................ 8

Research Questions and Hypotheses .......................................... 9

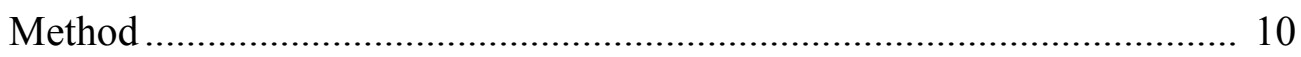

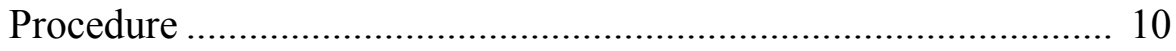

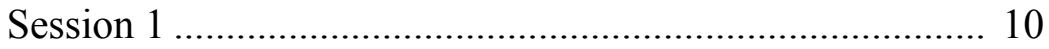

Session 2 ........................................................... 10

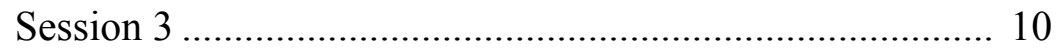

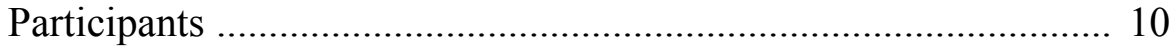

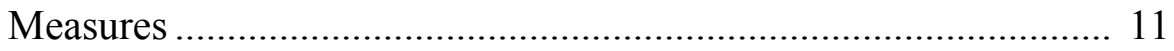

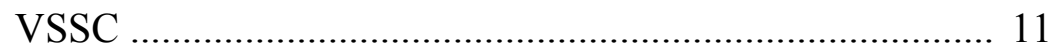

Magic Show Interview and Lost Monkey Interview .......... 12

Theory of Mind Battery ............................................... 13

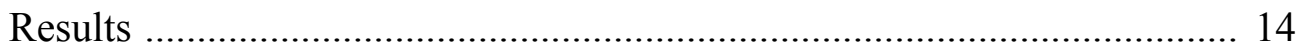

Descriptive Results .............................................................. 14

Research Questions and Hypotheses .......................................... 15

Research Question 1 ................................................... 15

Research Question 2 ................................................. 16

Research Question 3 .................................................. 17 
Additional Analyses ……………………………………............. 19

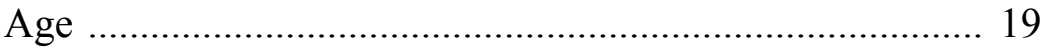

Regressions with Older and Younger Age Groups ............. 19

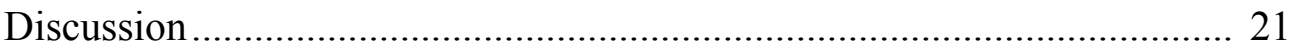

The VSSC and Suggestibility ………………………................... 22

Theory of Mind and Suggestibility …………………………......... 26

Theory of Mind and the Predictive Ability of the VSSC ............... 27

Limitations and Future Research ................................................... 29

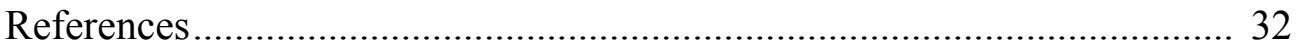

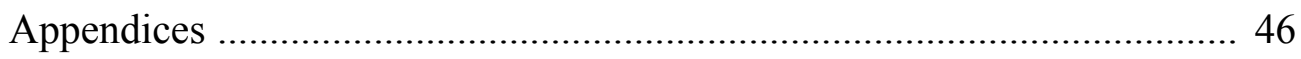

Appendix A: Theory of Mind Scale …………………………....... 46

Appendix B: Magic Show Interview and Lost Monkey Interview.. 48

Appendix C: The Video Suggestibility Scale for Children ............. 52

Appendix D: Magic Show Script ……………………………....... 56

Appendix E: Cover Letter ............................................................. 61

Appendix F: Consent Form ....................................................... 62

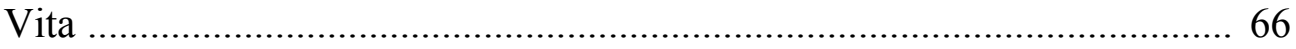


List of Tables

Table 1: $\quad$ Descriptive Statistics of Variables ....................................... 37

Table 2: $\quad$ Pearson Correlations between the Variables.......................... 38

Table 3: $\quad$ Summary of Hierarchical Regression Analyses Predicting

Assents to Misleading Questions about an Experienced

Event

Table 4: $\quad$ Summary of Hierarchical Regression Analyses Predicting

Assents to Misleading Questions about a

Non-Experienced Event .................................................. 40

Table 5: Descriptive Statistics of Variables by Group...

Table 6: Pearson Correlations Between the Variables with Older

Children.

Table 7: Pearson Correlations Between the Variables with Younger

Children.

Table 8: $\quad$ Summary of Hierarchical Regression Analyses Predicting

Assents to Misleading Questions about an Experienced

Event with Older Children.

Table 9: $\quad$ Summary of Hierarchical Regression Analyses Predicting

Assents to Misleading Questions about a

Non-Experienced Event with Older Children 


\section{Introduction}

Over the past 30 years, researchers have investigated with renewed interest a child's ability to provide accurate testimony for witnessed events in a suggestive interview situation (Ceci \& Bruck, 1993). In the last decade, children's suggestibility research has shifted to the study of individual differences that moderate susceptibility to suggestion. Instead of only focusing on the circumstances in which suggestibility occurs and age differences in suggestibility, research is now concentrating on the cognitive factors that underlie suggestibility. Proponents of the individual differences approach posit that higher levels of suggestibility reflect cognitive weaknesses (e.g., deficits in memory, theory of mind, intelligence, or language) or personality factors (e.g., suggestibility as a trait-like characteristic). Cognitive weaknesses are the individual difference characteristics that are most frequently related to why some children are more suggestible than others (reviewed in Bruck \& Melnyk, 2004).

Research is also deciphering the intricacies of suggestibility as a stable, measurable individual characteristic of children. Over the past few years, age differences have been a consistent finding in children's suggestibility, with preschool children being the most suggestible. While age is still considered an important variable, recent studies are more concerned with examining how various individual difference factors in suggestibility vary with age and affect recalled information and witnessed event testimony. Scullin, Kanaya, and Ceci (2002), discovered that there were minimal systematic relations between their suggestibility measure and the dependent measures (an experienced and a non-experienced event) among children under $4 \frac{1}{2}$ years of age. The authors also discovered that suggestibility was predictable across real and suggested situations, as well as question types, for children over the age of $41 / 2$. The authors also reasoned that the lack of findings for children under $4 \frac{1}{2}$ years of age may be due to deficits in theory of mind and executive function in younger children.

Theory of mind has been shown to develop between the ages of 3 and 5 and is sometimes linked to suggestibility (Bruck \& Melnyk, 2004). Generally, the research surrounding the link between theory of mind and suggestibility has been inconsistent. While most research relating children's suggestibility to theory of mind has viewed theory of mind as a dichotomous construct, Wellman and Liu (2004) posited that theory of mind develops in a sequence or developmental progression that may be assessed with a scale. The contemporary view of theory 
of mind, when examined in conjunction with children's suggestibility, may help clarify the relation between theory of mind and suggestibility.

The major objective of this study was to validate the Video Suggestibility Scale for Children (VSSC; Scullin \& Ceci, 2001) and a theory of mind scale as predictors of children's suggestibility in a single suggestive interview about an experienced event and a non-experienced event. Children, between the ages of 3 and 5 years old, completed the VSSC and engaged in theory of mind tasks. The relation between the scale measures and suggestibility about an experienced event and a non-experienced event was examined.

\section{Literature Review}

\section{Suggestibility}

Many different definitions of suggestibility exist in the literature. A frequently used and widely accepted definition is "the extent to which individuals come to accept and subsequently incorporate post-event information into their memory recollections" (Ceci \& Bruck, 1993, p. 404). Ceci and Bruck argued that this definition should be broadened, because in their view, suggestibility may occur during the encoding, storage, retrieval, and the reporting stages of memory for events. The type of suggestibility examined in this study is interrogative suggestibility, which focuses on the retrieval and reporting stages of suggestibility. Interrogative suggestibility is defined as "the extent to which, within a closed social interaction, people come to accept messages communicated during formal questioning, as a result of which their subsequent behavior response is affected"(Gudjonsson, 1984, p. 303).

Interrogative suggestibility can occur when children are interviewed about either an experienced event or a non-experienced event. In pressured interview suggestibility for an experienced event, a live event is witnessed or watched by the child. Following the event, the child is then asked suggestive questions regarding the event (Garven, Wood, Malpass, \& Shaw, 1998; Powell, Jones, \& Campbell, 2003). In pressured interview suggestibility for a nonexperienced event, children are questioned about an event that they did not witness or watch. If repeatedly interviewed or given strong positive or negative feedback in a single interview, children have been shown to attain very high rates of assent to suggestive questions in a nonexperienced event interview (Ceci \& Bruck, 1993). Assent to suggestive questions about a nonexperienced event can have implications for child sexual abuse cases and other cases that potentially involve coercive, suggestive techniques (Powell et al., 2003). A child may assent to 
suggestive questioning about sexual contact with an adult, which can lead to false testimony and incrimination of the adult, and consequently, prison (e.g., the Kelly Michaels' case).

\section{Children's Vulnerability to Suggestion}

Children who are between the ages of 3 and 6 years are the most vulnerable to suggestion in comparison with other children and adults (Ceci \& Bruck, 1998; Powell et al., 2003). This age group is particularly susceptible to interference and contamination in the recall of events due to various external influences. The contamination of memory occurs in the retrieval of general and specific event information (Farrar \& Goodman, 1992).

One theory of false memory in children is the fuzzy-trace theory. This theory is based on the distinction between verbatim representations and gist representations. Verbatim representations are the specific details of the event or subject that is being remembered. The gist representation is the general outline of (or general script for) the remembered event or subject. Verbatim representations are more easily clouded by interference effects and become more inaccessible than gist representations. Forgetting is characterized by the disintegration of traces of these kinds of representations.

According to the theory, children tend to have more of a verbatim memory for events, which can fade quickly or be easily overwritten, and have less of a gist memory for events. False memories occur because weakened verbatim memories can be more easily overwritten by interviewer suggestions or replaced with gist representations. In turn, gist representations may be falsely ascribed to events that are experienced (Reyna \& Lloyd, 1997). This false ascription can be problematic, especially in children who are asked yes-no types of questions in interview situations. Since young children do not remember the verbatim representation, they will be more inclined to respond "yes" and falsely recognize misinformation as being consistent with a gist representation of an event, and in turn, acquiesce to misinformation. Thus, according to fuzzytrace theory, false memories occur in two ways - as a result of the retrieval of gist memories when verbatim memories are called for, or the retrieval of the wrong verbatim memories.

Verbatim and gist memories are influenced by age and delay once these memories are distinguished. For example with age, older children are more capable of remembering original verbatim information, and resisting interference from gist memories in verbatim tasks. However, older children are also more likely to remember verbatim misinformation. After a sufficient 
delay, gist memories should dominate memory performance, and verbatim memories should be less accessible.

Assessment of Suggestibility in Children

In 2001, Scullin and Ceci developed the Video Suggestibility Scale for Children (VSSC), which is an extension of Gudjonsson's research (1984). Scullin and Ceci preserved the major components of the Gudjonsson Suggestibility Scales (GSS), but used a videotape for the stimulus, which is analogous to an actual eyewitness situation when compared to the GSS audiotapes (Gudjonsson, 1984, 1987). The first component of the scale reflects the amount of information provided during open-ended questioning (Memory Recall). The measures of individual differences in suggestibility consist of acquiescence to suggestive questioning (Yield) and the extent to which individuals will change their answers due to feedback from the interviewer (Shift) - a two-factor measure.

The VSSC has been found to produce similar levels of internal consistency in Yield and Shift as the GSS (Scullin \& Ceci, 2001). Each age group (3-year-olds, 4-year-olds, and 5-yearolds), as the ages increased, recalled significantly more information in the Memory Recall component of the scale. Along with an increase in Memory Recall, there was also an increase in Shift, the measure of responsiveness to feedback from the interviewer, as the ages of the children increased. The increase in Shift may be due to the increasing awareness of social pressure and improved social cognition (theory of mind) in children between the ages of 3 and 5 years (Scullin \& Bonner, 2006).

For the older children, the Yield subscale was a significant predictor of whether a child assented to a non-experienced event in the free recall portion (compared to Shift). Total suggestibility (the sum of Yield and Shift) was also found to be a strong predictor of assent to a non-experienced event among the older children (Scullin et al., 2002). Total suggestibility was found to be correlated with 10 of the 11 repeated interview dependent measures (assent to misleading or accurate questions) in children over 54 months of age. In addition, Yield was a better predictor than Shift among older children, significantly predicting 7 out of the 11 dependent measures.

In the younger children, Yield was only a significant predictor of the tendency to say "yes" to the misleading yes-no questions about an experienced event. These 5 misleading yes-no questions were similar to the questions of the Yield scale (Scullin et al., 2002). None of the 
VSSC suggestibility measures generalized significantly across other question types or response types for younger children. In two studies, a strong negative correlation was found between Yield and Shift in the younger children, but not among older children (Scullin et al., 2002; Scullin \& Bonner, 2006). Younger children had a tendency to change most of their initial "no" responses to the leading yes/no questions to "yes" when confronted with negative feedback. This finding implies that young children may not be able to adopt the point of view of the interviewer, suggesting deficits in theory of mind.

Scullin and Bonner (2006) examined individual differences in theory of mind, inhibitory control, and three measures of suggestibility in 3- to 5-year-old children. The authors explored Yield, Shift, and accuracy in response to misleading questions during a single pressured interview about an experienced event. Scullin and Bonner found that theory of mind predicted suggestibility about an experienced event, and inhibitory control was a moderator variable, which influenced children's sensitivity to social pressure during an interview. The authors found that the construct validity of Shift may improve as a child's inhibitory control develops. Theory of mind, which was directly predictive of pressured interview suggestibility for an experienced event, may also prove to be a useful individual difference construct when identifying children who are more prone to interviewer suggestions. However, Scullin and Bonner used a single false belief task to measure theory of mind, which may not have fully captured the individual differences related to suggestibility and theory of mind.

\section{Theory of Mind}

Theory of mind is defined as a child's ability to take another individual's perspective and to be aware that other individuals can have false beliefs (Astington, 1993). Multiple studies have investigated this construct in children's development, and it has been found consistently that theory of mind improves between the ages of 3 and 5. Theory of mind tasks generally center around false beliefs, or more specifically, mental-state understanding. Mental-state understanding is inherent in a false-belief task because it requires the understanding that mental states are internal, and are distinct from real-world events and overt behavior. This understanding is the distinction between mind and world, as well as others' minds and the world (Wellman, Cross, \& Watson, 2001).

Much of the past research on theory of mind used a wide range of tasks and had contradictory age findings. Wellman and Liu (2004) recently suggested that theory of mind is not 
a dichotomous construct reflecting either an acquisition of theory of mind or a lack of theory of mind. Instead, they argued that theory of mind develops in a sequence or developmental progression. The authors integrated the primary findings in theory of mind research into a set of methodologically comparable tasks that follow a developmental progression (Wellman \& Liu, 2004). This progression is based on the development of different conceptual constructs of theory of mind, including desires, emotions, knowledge, and beliefs.

The four states assessed in this scale (desires, beliefs, knowledge, and emotions) are all similar mentally and reflect understanding of discrepancies from reality. For example, a person may have different desires about something than another person, or a person may have different beliefs about a situation than another person. The findings from Wellman and Liu's study indicate that children become aware that two persons can have different desires for the same object before they can become aware that two persons can have different beliefs about the same object. Later, older preschoolers can more accurately understand the difference between real and apparent emotion.

Wellman and Liu (2004) list many advantages of using a theory of mind scale, as opposed to using separate tasks. For example, a scaled set of tasks can more comprehensively capture a child's development of understanding and mental states across a range of conceptions. This scaled set of tasks provides stronger evidence for a developmental progression than do inferences from the means of groups on different tasks. In addition, a scale would be more useful in measuring individual differences in theory of mind and other factors in children. Other researchers have argued that the use of one dichotomous task to measure theory of mind is not appropriate. For example, Bloom and German (2000) state that false belief tasks are difficult for children to understand and pass independent of the requirement to reason about false belief and to reason about any sort of representation. Bloom and German also posit that several mechanisms are inherent in theory of mind to pass a false belief task (e.g., inference of referential intentions, learning the meanings of words, imitation, initiating pretend play). Overall, a scale can help broaden the construct of theory of mind, and help explain deviations in findings that occur because of how the construct is conceptualized (Wellman \& Liu, 2004). 


\section{Theory of Mind and Suggestibility}

Many studies have established a connection between theory of mind and suggestibility. Between the ages of 3 and 5, there is a decline in suggestibility that coincides with theory of mind improvements. Studies that have found a relation have typically discovered a negative relation associating higher levels of theory of mind with less suggestibility, while holding age constant (Bruck \& Melnyk, 2004). Bruck and Melnyk argued that there are conflicting theoretical predictions that can arise from better developed theory of mind. One prediction is that children who can easily adopt another person's point of view can also have a belief that is different from their own belief, and can therefore more easily reject the other person's differing belief (i.e., realize that a person's statements can contain misinformation; i.e., lowered suggestibility). However, another theoretical prediction that can arise from better developed theory of mind is that children who understand that another person can have a different belief from one's own, can accept the differing belief (even though the child knows that it is wrong) due to social influences and factors (i.e., increased suggestibility). The relation between theory of mind and suggestibility appears to be an individual difference characteristic that may enable differing strategies to be used by a child in a suggestive interview: either resisting suggestion or acquiescing to the suggestions (Scullin \& Bonner, 2006).

Welch-Ross, Diecidue, and Miller (1997) investigated how the understanding of conflicting mental representations in preschoolers related to suggestibility about a story. The authors used appearance-reality tasks to measure children's understanding of conflicting mental representations. Welch-Ross and colleagues found a negative relation between performance on the appearance-reality tasks and the acceptance of misinformation. The authors concluded that acquisition of understanding conflicting mental representations can buffer against the acceptance of misinformation.

More recently, Quas and Schaaf (2002), did not find a relation between theory of mind and suggestibility in a repeated interview study. Quas and Shaaf, however, only used one measure of theory of mind (false-belief tasks) to assess the relation. Other studies have also failed to find a consistent relation using multiple tasks of theory of mind in relation to suggestibility (Bruck \& Melnyk, 2004). This problem may be related to the different representational understandings reflected in the measures used. Due to the number of conflicting studies with a variety of theory of mind measures and contradictory evidence, the hypothesis that 
theory of mind is a mechanism that accounts for children's suggestibility is problematic and needs further investigation. The relation between the variables is in question because theory of mind has been used to predict both increases and decreases in children's suggestibility. Thus, the relation between suggestibility and theory of mind can be clarified by the use of multiple measures of theory of mind assessing many different dimensions of the construct, as in the Wellman and Liu scale (2004).

\section{Rationale}

Building upon the investigations of Scullin and Bonner (2006), this study will evaluate more rigorously the hypothesis that children with better theory of mind skills are less suggestible, and among children who have developed theory of mind, measurement of suggestibility will be more consistent across different kinds of questions and situations regardless of chronological age. This study will also investigate individual differences in suggestibility in children who are most prone to suggestion. For those in the mental health field, awareness of which children are more suggestible is of great importance because this knowledge can alert them to be cautious in their interviews with children who are "highly suggestible" or who have deficits in theory of mind. In addition, for those involved with the legal system, knowledge of a child's suggestibility level can alert forensic interviewers of the risk of using certain suggestive techniques in eliciting testimony from children.

\section{Statement of the Problem}

This study sought to validate the Video Suggestibility Scale for Children (VSSC) by assessing Yield and Shift as measures of pressured interview suggestibility about an experienced event and a non-experienced event in which there was a high level of pressure from the interviewer to provide specific answers about target events. This study also proposed to examine the relation between theory of mind, Yield, Shift, and pressured interview suggestibility, and whether theory of mind adds to Yield and Shift in predicting pressured interview suggestibility. The basic outcome variables (dependent variables) include: pressured interview suggestibility about an experienced event and pressured interview suggestibility about a non-experienced event. The predictors (independent variables) include: Age, Yield, Shift (subscales of the VSSC), Total Suggestibility, and theory of mind as measured by the theory of mind scale (Wellman \& Liu, 2004). 


\section{Research Questions and Hypotheses}

Research Question 1.

How are Yield, Shift, and Total suggestibility related to pressured interview suggestibility about an experienced event and a non-experienced event?

Hypothesis 1. Yield, Shift, and Total Suggestibility will be positively related to pressured interview suggestibility about an experienced event.

Hypothesis 2. Yield, Shift, and Total Suggestibility will be positively related to pressured interview suggestibility about a non-experienced event.

Research Question 2.

How is theory of mind related to pressured interview suggestibility about an experienced event and a non-experienced event?

Hypothesis 3. Theory of mind is expected to be negatively related to pressured interview suggestibility about an experienced event.

Hypothesis 4. Theory of mind is expected to be negatively related to pressured interview suggestibility about a non-experienced event.

Hypothesis 5. When age is controlled, the magnitude of the relationship between pressured interview suggestibility for an experienced event and theory of mind will decrease.

Hypothesis 6. When age is controlled, the magnitude of the relationship between pressured interview suggestibility for a non-experienced event and theory of mind will decrease.

\section{Research Question 3.}

Does theory of mind add to the predictive ability of the VSSC?

Hypothesis 7. Theory of mind, as measured by the theory of mind scale, will act as a predictive factor of suggestibility about an experienced event, over and above suggestibility as measured by the VSSC, in that the attainment of theory of mind skills may be an individual difference factor related to suggestibility.

Hypothesis 8 . Theory of mind, as measured by the theory of mind scale, will act as a predictive factor of suggestibility about a non-experienced event, over and above suggestibility as measured by the VSSC, in that the attainment of theory of mind skills may be an individual difference factor related to suggestibility. 


\section{Method}

\section{Procedure}

Session 1. The preschoolers in the first session viewed the 5-minute video entitled "Billy's Birthday Party." The children watched the entire video in a large group in a classroom. If a child was absent the day of the video watching, he or she watched it alone as soon as he or she returned to school. After watching the video, the children were administered the theory of mind scale by a trained research assistant. Following this, the children were administered the interview about the birthday party using the VSSC by the same research assistant.

Session 2. The following week, the children watched a magic show in large groups (i.e., as a class). The magician's performance was scripted, but videotaped to record any unusual events that occurred. A confederate posed as a magician and performed a number of tricks. The following tricks were performed: colors magically appeared in a coloring book, broccoli appeared as a snack, carrots appeared for a bunny, and the magician guessed the correct color of the crayon a child selected from a box of crayons. The show lasted approximately 15 minutes.

Session 3. During the following week, the children were interviewed individually about what happened in the magic show using the suggestive magic show interview. The interviewer was not the same interviewer the child had from the birthday party interview. The children were questioned suggestively as in the birthday party interview. In addition to the magic show interview, the children were interviewed about a non-experienced event (the lost monkey).

\section{Participants}

Ninety-one children in the age range of 3 to 5 years were recruited from local preschools. To have .80 power to detect medium effects $(r=.30)$, a sample of at least 84 preschoolers was required (Cohen, 1988). This age range was utilized because it reflects a period of theory of mind development, and because theory of mind and suggestibility have been shown to have an inconsistent relation during this age range (Bruck \& Melnyk, 2004).

Upon receiving a letter of permission from the preschools to conduct the study, the parents of the children were given consent forms and general information about the study (see Appendices E and F). Children were excluded who had any disabilities because replication and validation of the measures requires a normal population of preschoolers. In addition, children with English as a second language were also excluded. The measures require adequate language 
skills, and language is also highly negatively correlated with suggestibility (Bruck \& Melnyk, 2004).

Measures

The Video Suggestibility Scale for Children (VSSC)

Scullin \& Ceci (2001) developed The Video Suggestibility Scale for Children (VSSC).

This scale was modeled after the Gudjonsson Suggestibility Scale (Gudjonsson, 1984; 1987) and contains a 5-minute video of a child's birthday party. Following the video, the children were administered a suggestive interview about the video. The interview contained a free recall component and 18 probe questions. Fourteen of these questions contained misleading information. The interviewer began the free recall by asking the children what they remembered in the video. This phase of the scale was completed in a non-suggestive, open-ended manner. The children were probed during the free recall with open-ended questions (e.g., "What else happened?"). The number of correctly identified people or events was coded as a Memory Recall score. These correctly identified elements could be key characters, key events, and other things that happened in the script. Each correctly remembered detail about the birthday party was given 1 point. The coding scheme used in the present study was analogous to the coding in Memon, Walk, Bull, and Koeknken (1997) in which two coders categorized the written transcripts of the children's responses to free recall questions (and double-checked with the video taped interviews) into four categories: persons, objects, actions, and surroundings. The four categories were totaled to form one total Memory Recall score. A high Memory Recall score indicated that more information was recalled from the video.

Two research assistants, who had not administered the VSSC, coded the transcripts for the Memory Recall portion of the VSSC. The coders attained a high reliability by coding transcripts from a prior study. The final coding revealed a high intraclass correlation $(r=.97)$. After classifying each piece of information from the transcripts, the categories were totaled as a measure of a child's overall Memory Recall.

When looking specifically at the probe questions, if the child assented to the misleading question, this was scored as a Yield. The Yield subscale contained 4 accurate leading questions (with a correct response of "yes") and these questions were not scored in this subscale. Therefore, the possible range was 0 to 14 (Scullin \& Ceci, 2001). After the first nine questions, the child was told that he or she made several mistakes and that they were going to be asked the 
questions again to see if they can do better. After this feedback was given, if the child changed his or her answer due to the incorporation of the feedback, this was scored as a Shift. These changes in response from the initial questioning were given 1 point each. The changes in the accurate questions were included in this subscale, so the possible range of scores included 0 to 18. Total Suggestibility was defined by the sum of Yield and Shift and the score ranged from 0 to 32 (see Appendix C). In addition, answers that included "I don't know" or "I'm not sure" were coded as non-yielding, meaning correct (i.e., scored as a "no").

The Magic Show Interview and the Lost Monkey Interview

The magic show interview was a shorter version of the interview used by Scullin and Bonner (2006). Approximately one week after viewing the live magic show, the children were asked a series of questions about what happened during the show. The interview consisted of 10 questions about what actually occurred during the show. Five of the 10 questions contained information that did not actually occur. The questions were arranged in a hierarchy so that the misleading questions became progressively far-fetched and improbable (Garven et al., 1998). If the child denied that an event occurred, the interviewer told the child to think really hard about the question because other children said that the magician had done these things. The question was repeated again. If the child accepted the suggestion, the interviewer gave positive feedback such as, "Good job! Thank you! You're so helpful!" If the child still maintained that the event did not happen, the interviewer moved to the next question with no positive feedback. The responses were coded for overall accuracy. For a complete description of the magic show interview, see Appendix B.

The children received a point for answering questions about the details correctly (i.e., not assenting to the interviewer's suggestions by responding "no" or "I don't know"). The scores were calculated by summing the accurate responses to misleading questions to create the misleading accurate variable (with a possible range of 0 to 5). In order to examine the influence of feedback, children's changes in their original responses were calculated as well. This portion of the interview was calculated as a proportion score for the percentage of times a child shifted his or her answer out of the total number of possible shifts.

The children were also interviewed about a non-experienced event following the experienced event interview - the Lost Monkey interview. The interview about the nonexperienced event followed the same guidelines as the interview about the experienced event. 
The situation included a lady who has lost her monkey, George, and elicits the help of the children to find her monkey. The questions resembled the questions in the magic show interview and were scored the same way as in the Magic Show interview (see Appendix B). The scores were calculated by summing the accurate responses to misleading questions to create a misleading accurate variable for the monkey interview. Since all the questions in the interview were essentially misleading (because the event did not occur), the possible range was 0 to 10 . Again, the influence of feedback was examined in a similar fashion as in the magic show interview.

\section{Theory of Mind Battery}

The theory of mind battery, from Wellman and Liu (2004), encompassed five tasks and within each task, two key questions were asked. This five-stage scale represents a continuous measure of the theory of mind progression and is intended to replace the use of one task (i.e., a single false belief task) to capture this developmental construct. The first question addressed the content of the scenario by asking about the central character's mental state or behavior. The second question was a control question about the reality or expression of another individual's mental state (Wellman \& Liu, 2004). Therefore, this two-part format ensured that the child understood the concept of the scenario, and then a question was asked to see if that particular level of theory of mind is present.

The scale took approximately 10 to 15 minutes to administer due to the two-part question format and the use of different props for each stage in the progression. The child was considered to have "passed" the task if he or she answered both questions appropriately, receiving a point for each question answered appropriately. To be scored as correct, or to "pass" this task, the child must have answered the target question opposite from his or her answer to the stage question. The stage question was the knowledge question to determine if the child understood the basic information in the task. The target question was the actual question that targets the dimension of theory of mind that was being assessed. The score ranged from 0 to 5 in which the child was given 1 point for every task passed (Wellman \& Liu, 2004). Wellman and Liu (2004) found that there was a main effect for age when testing this scale in that with increasing age, children passed more tasks (i.e., also found in the current study). The relation between age and scale score was found to be $r=.64$. In addition, the items on the scale were found to form a Guttman scale based on equivalent sample sizes and multiple testing sessions. These items on the 
scale, as assessed by Green's index of consistency, a measure of internal consistency reliability, are highly scalable (the coefficient of reproducibility was .56; Wellman \& Liu, 2004). Reliability or validity indices are not available due to the novelty of the scale. The tasks in the five-stage scale are briefly described below, and can be found in Appendix A.

Task 1: Diverse Desires - This task showed how the child and a toy figure could have different desires. Task 2: Diverse Beliefs - Children in this task were asked about the location of a cat depending on the differing beliefs of the child and a toy figure. Task 3: Knowledge Access - Children were shown a drawer that had an object inside of it. Based on their knowledge of what was inside the drawer, the children were asked about their knowledge of the contents of the drawer and a toy figure's knowledge of the contents of the drawer. Task 4: Contents False Belief - The children were asked about the contents of an object. After the contents of the object were revealed, the children were asked about the toy figure's knowledge of the contents of the object. Task 5: Real-Apparent Emotion - The children were required to identify a few emotions. The children were told a story of a toy figure that possessed real emotions and "fake" emotions based on the story. The children were then asked to discriminate how the toy figure felt based on these differing types of emotions.

\section{Results}

\section{Descriptive Results}

Table 1 depicts the descriptive statistics of the variables. The mean age of 3- to 5-yearolds in the sample was comparable to Scullin and Bonner $(2006 ; M=50.86, S D=7.45$ versus $M=52.35, S D=7.87$ in Scullin and Bonner). Memory recall, Yield, Shift, and Total Suggestibility scores were also comparable. In Scullin and Bonner, theory of mind was assessed using a single contents false belief task that had a range of 0 to 4 . Conceptually, the use of a single task has been hypothesized to not fully capture the construct of theory of mind. Therefore, the measure used in this study, a series of 5 theory of mind tasks scored as pass/fail from 0 to 5 , produced a range of good variability $(M=2.58, S D=1.20)$ and reflects the developmental progression of theory of mind as it is related to age. Although this approach in measuring theory of mind was slightly different than in Scullin and Bonner (conceptually and in terms of range), the mean theory of mind score was similar (for Scullin and Bonner, $M=2.44, S D=1.46$ ). Among the dependent variables, children assented to proportionately fewer misleading questions about the experienced event (60\%) than to misleading questions about the non-experienced event 
$(76 \%)$, paired $t(90)=-7.01, p<.001$. These findings are similar to Scullin and colleagues (2002), who found that children were more accurate about a true (experienced) event compared to accuracy for a suggested (non-experienced) event.

\section{Research Questions and Hypotheses}

Research Question 1. How are Yield, Shift, and Total suggestibility related to pressured interview suggestibility about an experienced event and a non-experienced event?

Hypotheses 1 and 2. Yield, Shift, and Total Suggestibility will be positively related to pressured interview suggestibility about an experienced event and a non-experienced event. These hypotheses were examined using Pearson correlations. Table 2 depicts the zero-order Pearson correlations between the variables. As hypothesized, Yield $(r=.29)$ and Total Suggestibility $(r=.32)$ were significantly positively related to assent to misleading questions in an experienced event interview, as in Scullin and Bonner (2006). However, Shift was not related to suggestibility in an experienced event interview. Contrary to hypothesis 2, Yield, Shift, and Total Suggestibility were not related to assent to misleading questions in a non-experienced event interview.

Further examination addressed correlations between the major variables and initial responses (before pressure and feedback) to the questions in an experienced event interview and a non-experienced event interview (i.e., addressing the construct validity of Yield). Pearson correlations revealed significant relations between the major variables and the experienced event interview, but not a non-experienced event interview. More specifically, initial assents to misleading questions (before pressure and feedback) in the magic show interview correlated moderately with age $(r=-.39)$, theory of mind $(r=-.27)$, Yield $(r=.40)$, and Total Suggestibility $(r=.37)$. The moderate correlation between the initial assents to misleading questions in an experienced event interview and Yield is not surprising in that Yield is a measure of initial responses to questions by an interviewer. Thus, this finding demonstrates the construct validity of Yield as a measure of initial responses to questions from an investigator in a forensic interviewing situation.

The construct validity of Shift was examined by addressing the relation between Shift and the proportion of inaccurate answer changes in response to interviewer feedback in the experienced and non-experienced events. A proportion score was created for the experienced event and non-experienced event interview questions with shifting from a "no" (or "I don't 
know") response to a "yes" response as the numerator (coded as a 1 for shifting the answer and 0 if no shift occurred). The denominator reflected all the possible shifts that could have occurred in answering the interview questions (i.e., responding "no" or "don't know" the first time). Thirteen children were excluded from analyses for the magic show interview because these children responded affirmatively to every question in the interview $(\mathrm{N}=78)$. This pattern of responses does not allow for the investigation of Shift due to the interviewer's inability to provide the child with pressure or feedback after a "yes" response. Fourteen children were excluded from analyses for the monkey interview as well $(\mathrm{N}=77)$.

This proportion was examined in the magic interview in the full sample and was found to have similar properties as Scullin and Bonner $(2006 ; M=.39, S D=.42$; for Scullin and Bonner, $M=.44, S D=.41$; see Table 1). Scullin and Bonner did not use a non-experienced event stimulus, but the monkey interview inaccurate shift proportion score statistics for the full sample produced a mean of $.44(S D=.42)$. Additionally, the proportion scores were examined in relation to Shift. In the study by Scullin and Bonner, Shift (but not Yield) was significantly related to the proportion of inaccurate shifts in the pressured interview (experienced event; $r=$ $.49, p<.01)$. In the current study, Shift was not significantly related to the proportion of inaccurate shifts in the experienced event interview in the full sample $(r=.13, n s)$. However, the proportion of inaccurate shift in the experienced interview was significantly related to Total Suggestibility $(r=.24, p<.05$; see Table 2$)$.

Research Question 2. How is theory of mind related to pressured interview suggestibility about an experienced event and a non-experienced event?

Hypotheses 3 and 4. Theory of mind is expected to be negatively related to pressured interview suggestibility about an experienced event and a non-experienced event. These hypotheses were examined using Pearson correlations. Table 2 depicts the zero-order Pearson correlations between the variables. Consistent with hypothesis 3, theory of mind, as measured by the progressive theory of mind scale, was significantly negatively related to assent to misleading questions in an experienced event interview $(r=-.30)$. Hypothesis 4 was not supported in that theory of mind was not significantly negatively related to assent to misleading questions about a non-experienced event.

Hypotheses 5 and 6 . When age is controlled, the magnitude of the relationship between pressured interview suggestibility for an experienced event and theory of mind and a non- 
experienced event and theory of mind will decrease. Scullin and Bonner (2006) found that theory of mind scores were positively related to fewer misleading question errors (accuracy) in the pressured interview even after age was controlled. Partial correlations (see Table 2) revealed a decrease in the magnitude of the relation between pressured interview suggestibility for an experienced event and theory of mind $(r=-.21)$, rendering the relation non-significant.

Research Question 3. Does theory of mind add to the predictive ability of the VSSC? Hierarchical regressions were conducted to examine if age, theory of mind, Yield, Shift, and the related interactions (Yield and theory of mind and Shift and theory of mind) predicted performance in an experienced event interview and a non-experienced event interview.

Hypothesis 7 . Theory of mind, as measured by the theory of mind scale, will act as a predictive factor of suggestibility about an experienced event, over and above suggestibility as measured by the VSSC, in that the attainment of theory of mind skills may be an individual difference factor related to suggestibility.

Before the hierarchical regressions were performed, the independent variables were examined for multicollinearity. Results of the variance inflation factor (all less than 1.4), and multicollinearity tolerance (all greater than .75) suggested that the estimated $\beta$ s (i.e., and therefore the independent variables) were stable in the following regression models. As seen in Table 3 with suggestibility in an experienced event interview as the outcome variable, Step 1 of the model with age alone as a predictor was significant, $F(1,89)=5.72, p<.05, R^{2}=.06$. In Step 2 , the addition of theory of mind as a predictor variable resulted in a significant model, $F(2,88)=$ $5.01, p<.01$. This equation alone accounted for $10.2 \%$ of the variance in suggestibility in an experienced event. Addition of theory of mind to the equation with age resulted in a significant increment in $R^{2}, \Delta F(1,88)=4.10, \Delta R^{2}=.04$. In Step 3, Yield and Shift were added together, which again resulted in a significant model, $F(4,86)=4.22, p<.01$. Addition of Yield and Shift to the equation resulted in a significant increment in $R^{2}, \Delta F(2,86)=3.19, \Delta R^{2}=.06$. After Step 3 , the equation accounted for $16.4 \%$ of the variance in suggestibility in an experienced event.

Because of the hypothesis that theory of mind may serve as a predictor variable between suggestibility as measured by the VSSC and suggestibility in an experienced event, interactions between theory of mind and Yield and theory of mind and Shift were assessed. These interactions were assessed and the full model (Step 4) was significant, $F(6,84)=3.49, p<.01$, 
$R^{2}=.20$, but neither interaction was significant, $\Delta F(2,84)=1.85, n s, \Delta R^{2}=.04$. The interactions were not retained in the model because they were not significant (see Table 3 ).

In the final model without the interactions (Step 3), controlling for age, theory of mind, and Shift, Yield was a significant unique predictor of suggestibility in an experienced event interview, $\beta=.27, p<.05$. This significant positive relation suggests that higher Yield scores are related to greater assent to misleading questions in an experienced event interview (more suggestibility). Because theory of mind was not a significant unique predictor of pressured interview suggestibility over and above suggestibility as measured by the VSSC, this hypothesis was not supported.

Hypothesis 8 . Theory of mind, as measured by the theory of mind scale, will act as a predictive factor of suggestibility about a non-experienced event, over and above suggestibility as measured by the VSSC, in that the attainment of theory of mind skills may be an individual difference factor related to suggestibility.

Multicollinearity was examined in the hierarchical regressions. The variance inflation factors were all less than 1.4, and tolerance was greater than .75 suggesting that the independent variables were not highly correlated and were stable in the regression models. As seen in Table 4 with suggestibility in a non-experienced event interview as the outcome variable, Step 1 of the model with age alone as a predictor was not significant, $F(1,89)=.06, n s$. In Step 2, the addition of theory of mind as a predictor variable resulted in another non-significant model, $F(2,88)=.94$, $n s$. Yield and Shift added together resulted in a non-significant model, $F(4,86)=.83$, ns. After Step 3, the equation accounted for $3.7 \%$ of the variance in suggestibility in a non-experienced event (see Table 4).

Interactions were assessed between theory of mind and Yield and theory of mind and Shift. These interactions were assessed and the full model (Step 4) was not significant, $F(6,84)=$ $1.15, n s$, and neither interaction was significant. With suggestibility in a non-experienced event interview as the outcome variable, the model only accounted for $7.6 \%$ of the total variance. Thus, hypothesis 8 was not supported in that theory of mind was not a predictive factor of suggestibility about a non-experienced event, over and above suggestibility as measured by the VSSC. 


\section{Additional Analyses}

Post-hoc analyses examined whether the relation of the VSSC variables and the theory of mind scale changed depending on whether children had attained a particular age or received specific scores on the theory of mind scale.

Age. Similar to the age breakdown of the Scullin et al. (2002) analyses, the sample was split into an older $(n=39)$ and a younger group $(n=52)$ with the break at 54 months of age. As seen in Table 5, the older group had a lower mean score on the Yield subscale than the younger group $(M=5.51$ vs. $M=8.25 ; t(89)=3.70, p<.01)$, and were less suggestible about the magic show $(M=2.38$ vs. $M=3.44)$ compared to the younger group, $t(89)=2.82, p<.01$. Comparable to the findings in Scullin and Bonner (2006) and Scullin and colleagues (2002), a negative correlation between Yield and Shift was found in the younger sample $(r=-.37)$. This relation was found to be not significant in the older age group (see Table 6). In the older group, theory of mind was significantly negatively related to suggestibility in an experienced event and a nonexperienced event ( $r=-.44$ for both). However, these relations were not significant in the younger age group (see Table 7). These findings suggest that a more developed theory of mind is related to fewer assents to misleading questions in both an experienced event interview and a non-experienced event interview among children over 54 months of age.

The proportion of inaccurate shifts was examined in the older and younger age groups. The descriptive statistics can be found in Table 5. In the magic show interview, the younger age group did not display any significant correlations between the suggestibility variables (i.e., age, Yield, Shift, and Total Suggestibility) and theory of mind and the proportion of inaccurate shifts. However, in the older age group (54 months of age and older), the proportion of inaccurate shifts in the magic show interview was found to be moderately correlated with theory of mind $(r=-.37, p<.05$; see Tables 6 and 7). In examining the monkey interview, the same pattern of results emerged with the correlation between the proportion of inaccurate shifts and theory of mind in the older age group becoming stronger $(r=-.50, p<.01)$.

Regressions with Older and Younger Age Groups. Examination of multicollinearity revealed low variance inflation factors (all less than 1.9), and tolerances (all greater than .69) suggesting the significance of the independent variables in the following regression models. As seen in Table 8, with suggestibility in the experienced event interview as the outcome variable in the older sample, Step 1 of the model with age alone as a predictor was not significant, $F(1,37)=$ 
$.12, n s$. In Step 2, the addition of theory of mind as a predictor variable resulted in a significant model, $F(2,36)=4.67, p<.05$. This equation alone accounted for $20.6 \%$ of the variance in suggestibility for an experienced event in children over 54 months of age. The addition of theory of mind to the equation with age resulted in a significant increment in $R^{2}, \Delta F(1,36)=9.20, \Delta R^{2}$ $=.21$. In Step 3, Yield and Shift were added together, which again resulted in a significant model, $F(4,34)=3.80, p<.05, R^{2}=.31$. Although Step 3 produced a significant model, the addition of Yield and Shift did not result in a significant increment in $R^{2}, \Delta F(2,34)=9.20, n s$. Overall, the model accounted for $30.9 \%$ of the variance in suggestibility in an experienced event. In Step 4, the interactions of Yield and theory of mind and Shift and theory of mind were found to be not significant, although these additions still resulted in a significant model, $F(6,32)=2.80$, $p<.05, R^{2}=.34$, but not a significant increment in $R^{2}, \Delta F(2,32)=.86, \Delta R^{2}=.04$. Overall, including Step 4, the model accounted for $34.4 \%$ of the variance in suggestibility in an experienced event (see Table 8).

In the final model (Step 3), controlling for age, Yield, and Shift, theory of mind was a significant unique predictor of assent to misleading questions in an experienced event interview, $\beta=-.48, p<.01$. Yield was also a significant unique predictor of assent to misleading questions in an experienced event interview, $\beta=.34, p<.05$. This beta coefficient was larger than in the full sample, $\beta=.27, p<.05$, where theory of mind was nonsignificant in Step 3, $\beta=-.21$, ns.

With suggestibility in a non-experienced event interview in the older sample as the outcome variable, Step 1 of the model with age as the sole predictor was not significant, $F(1,37)$ $=1.25, n s$. In Step 2, the addition of theory of mind as a predictor variable resulted in a significant model, $F(2,36)=4.30, p<.05$. The addition of theory of mind to the equation with age resulted in a significant increment in $R^{2}, \Delta F(1,36)=7.13, \Delta R^{2}=.16$. This equation alone accounted for $19.3 \%$ of the variance in suggestibility for a non-experienced event in children over 54 months of age. In Step 3, Yield and Shift were added together, which again resulted in a significant model, $F(4,34)=2.94, p<.05, R^{2}=.26$. The addition of Yield and Shift to the equation with age and theory of mind did not result in a significant increment in $R^{2}, \Delta F(2,34)=$ 1.47 , $n s$. Overall, the model accounted for $25.7 \%$ of the variance in suggestibility in a nonexperienced event. In Step 4, the interactions of Yield and theory of mind and Shift and theory of mind were added and found to be significant in the model, $F(6,32)=3.21, p<.05, R^{2}=.38$. The addition of the interactions to the equation did not result in a significant increment in $R^{2}$, 
$\Delta F(2,32)=3.05, n s$. The individual interactions were examined in the model and the interaction of Yield and theory of mind was significant, but the Shift and theory of mind interaction was not significant (see Table 9). Overall, the final model, including Step 4, accounted for $37.6 \%$ of the variance in suggestibility in a non-experienced event.

In the regressions, controlling for age, Yield, Shift, and the interactions, theory of mind was a significant unique predictor of assent to misleading questions in all steps in the model for a non-experienced event interview in the older sample, $\beta=-.39, p<.05$ (in Step $4 ; \beta=-.43$, in Step 3; see Table 9). The interaction of Yield and theory of mind was also a significant unique predictor of assent to misleading questions in the final step of the model for a non-experienced event in the older sample, $\beta=.49, p<.05$.

For the younger sample (53 months and younger), the regression models were not significant. With suggestibility in an experienced event interview as the outcome variable, Steps 1 through 4 of the model were not significant, $F(6,45)=.816$, $n s$ (for Step 4), with this equation only accounting for $9.8 \%$ of the total variance. Thus, theory of mind was not a predictive factor of suggestibility about an experienced event, over and above suggestibility as measured by the VSSC for children 53 months and younger. For suggestibility in a non-experienced event as the outcome variable in the younger sample, Steps 1 through 4 of the model were not significant $F(6,45)=.285, n s$ (for Step 4 ), with this equation only accounting for $3.7 \%$ of the total variance. In conclusion, compared to the older sample, theory of mind was not a predictive factor of suggestibility about an experienced event and a non-experienced event, over and above suggestibility as measured by the VSSC for children 53 months and younger.

\section{Discussion}

The major objective of this study was to validate the Video Suggestibility Scale for Children (VSSC; Scullin \& Ceci, 2001) as a predictor of children's accuracy and suggestibility in a single suggestive interview about an experienced event and a non-experienced event. The study sought to examine a measure of children's suggestibility by using assent to misleading questions (Yield), pressure to change original responses when given mild social feedback (Shift) as predictors of pressured interview suggestibility in a single, highly suggestive interview about an experienced event (i.e., a magic show) and a non-experienced event (i.e., a lost monkey). Another major objective of this study was to examine the relation between theory of mind and children's accuracy about an experienced and a non-experienced event. The study also sought to 
assess the developmental progression of theory of mind skills as related to the suggestibility measures of Yield and Shift.

In the full sample, the main findings of this study include: 1) Yield and Total Suggestibility were significantly positively related to assent to misleading questions in a single suggestive interview about an experienced event, but not a non-experienced event; 2) theory of mind performance, as measured by a theory of mind Guttman scale, was significantly negatively related to suggestibility about an experienced event, but not about a non-experienced event. However, when age was controlled, the relation between theory of mind and suggestibility about an experienced event decreased to non-significance; 3 ) theory of mind added to the ability of age, Yield, and Shift to predict suggestibility about an experienced event, but not a nonexperienced event. Additionally, for the older age group (54 months and above), theory of mind predicted pressured interview suggestibility about an experienced event and a non-experienced event over and above suggestibility as measured by the VSSC.

Related to the third major finding, in post hoc analyses comparing older and younger age groups, the older age group's performance on the theory of mind scale added to the ability of age, Yield, and Shift to predict suggestibility in both an experienced event and a non-experienced event (i.e., theory of mind was predictive over and above the other independent variables). In comparison, the younger age group's performance on the theory of mind scale did not add to the ability of age, Yield, and Shift to predict suggestibility in both an experienced event and a nonexperienced event (preschoolers 53 months of age or younger). Therefore, theory of mind performance appears to be an important component of preschool-age children's suggestibility for children 54 months of age and over.

The VSSC and Suggestibility. In the examination of the relation between Yield, Shift, and Total Suggestibility and assent to misleading questions about an experienced event and a non-experienced event in the full sample, interesting results emerged. Yield and Total Suggestibility were significantly positively related to suggestibility for an experienced event, but not Shift. Previous studies have found a significant (positive) relation between Shift and pressured interview errors for misleading questions in an experienced event (Scullin \& Bonner, 2006). Perhaps Shift was not found to be correlated significantly with the pressured interviews because of differences in feedback (i.e., between the VSSC and the experienced event interview and the non-experienced event interview). The feedback in the VSSC is given after a number of 
questions have been asked and the feedback in the pressured interviews is given after every question (i.e., if the child responds "no" to the question). The feedback given in the pressured interviews may have been more pronounced and emphasized, and therefore the child may have remembered and internalized the feedback in the pressured interviews more than in the VSSC interview.

None of the VSSC components were significantly related to suggestibility for a nonexperienced event. In Scullin et al. (2002), it was found that Yield, Shift, and Total Suggestibility measures were positively related to a child's tendency to provide information over the course of multiple interviews about a non-experienced event and an experienced event, but only among older children. However, Scullin and colleagues note that these findings must be qualified in that there were no significant relations between Total Suggestibility and the criterion variables for the younger age group due to the insufficient power to detect medium-sized effects. In the older age group, however, the effect sizes were similar (within the medium to large range) for the experienced event and the non-experienced event. Perhaps a child's tendency to assent to misleading questions in a non-experienced event would emerge if more than one interview about the non-experienced event occurred.

In addition, all of the hypotheses related to the non-experienced event were not significant (i.e., except for the age-divided sample). The non-experienced event stimulus may not have been ecologically valid because it was a rare and outlandish event. Selecting a nonexperienced event that is more relevant to something a child may experience on a daily basis (e.g., playing on a playground, being punished by a parent, watching a movie) should be considered for future studies. A common non-experienced event may be more easily confused with an experienced event, and may be more ecologically valid for true forensic interviews that question children about events that are experienced regularly (e.g., doctor's appointments, supposed child abuse cases by a relative, being physically abused at school).

In examining the inaccurate shift proportion scores, differences emerged between Scullin and Bonner's (2006) findings and the current study's findings. In Scullin and Bonner's study, Shift was significantly related to the proportion of inaccurate shifts in the experienced event interview. In the current study, Shift was not significantly related to the proportion of inaccurate shifts in the experienced event interview in either the full sample or when the sample was broken into the older and younger age groups. This finding was surprising in that the interview format 
was similar to Scullin and Bonner. Perhaps the differences between different studies' samples can also help account for this discrepancy. For example, in Scullin et al. (2002), the sample used did not include many children in the 3-year-old range. The groups consisted of 25 younger children $(M=48.7$ months) and 25 older children $(M=60.4$ months $)$. In Scullin and Bonner (2006), the mean age of the participants was 52.16 months $(S D=7.69)$. Both these studies and others have used samples that are older than the sample used in this study. Since research has suggested that older children may Shift more than younger children, the young sample used in this current study may not have shifted their responses as much as the older samples shifted in the other studies.

In comparing Scullin and Bonner's robust finding of the relation between Shift and the proportion of inaccurate answer changes in the experienced event interview with the findings in the current study, their addition of a measure of inhibitory control may also help explain the differences. Scullin and Bonner found that the construct validity of Shift may depend more on the attainment of the level of inhibitory control reflected in a card sort task than upon chronological age. Inhibitory control involves the ability to inhibit an impulsive response or to inhibit task-irrelevant thoughts. Having well-developed inhibitory control skills can aid in avoiding saying something quickly and without thought in response to questions asked by an interviewer. Therefore, problems with inhibitory control may limit children's strategies for dealing with interviewer questions and feedback. A child with well-developed inhibitory control skills may be better able to think about the questions the interviewer is asking and respond correctly and change answers less frequently because of the ability to inhibit an impulsive response. The current study did not assess inhibitory control, and therefore, the individual differences with this aspect of executive function should be examined to clearly define the relation between Shift and the proportion of inaccurate answer changes in an experienced event.

Another explanation for the finding that Shift was not significantly positively correlated with other measures of suggestibility may be differences in the delay between the video and scale administration. The validity of Shift may have been compromised by a short (approximately 20 minute) delay between video administration and questioning. In Scullin and Bonner (2006), the researchers interviewed the children after a 1-day delay. One theory behind the length of delay states that a long delay may increase acquiescence in that after a long delay, original memory traces for the event may fade (Scullin \& Ceci, 2001). The children, therefore, 
may shift in response to interviewer pressure because they do not remember the events well and cannot challenge the misleading questions.

The fuzzy-trace theory may help explain individual differences related to age and event memory in that the delay between video administration and questioning (i.e., the VSSC) may affect the accessibility of verbatim memories, the incorporation of misinformation, and the interference from gist information. Allowing for a 1-day or longer delay is ecologically valid in that many interviewers do not question a child immediately after an event, and may better capture the construct of Shift in measuring suggestibility. The delay between an experienced event and the subsequent interview should be examined thoroughly in future studies to find the optimal delay to enhance the validity of Shift and measuring suggestibility.

Order effects may also have been present in the administration of the dependent measures (i.e., the experienced event interview and the non-experienced event interview). The interviews were not counterbalanced (i.e., children were administered the experienced event interview before the non-experienced event interview every time). This order of interview administration may have caused children to become fatigued or less motivated to answer questions after the experienced event interview. The fatigue and lack of motivation may have led the children to respond carelessly by answering "yes" more than "no" to every question asked. This format of answering questions may not have captured the construct of Shift, or have captured the concept of measuring pressured interview suggestibility for a non-experienced event adequately.

As found in Scullin and colleagues, and more recently Scullin and Bonner (2006), a moderate negative correlation was revealed between Yield and Shift among children less than 54 months of age. As mentioned in previous literature, this finding can be explained by the cognitive deficits in younger preschool-age children. Younger children may have a less sophisticated method of responding to an interviewer's questions. When confronted with negative feedback, some younger children have a tendency to shift all their original responses to "yes." However, if a child has assented to many of the first round interview questions (higher Yield scores), then he or she will have fewer chances to shift their original responses to "yes" in the second round of questioning. Thus, this negative correlation exists because shifts to "yes" are dependent upon the number of children's initial "yes" responses (Scullin \& Bonner, 2006). The negative correlation between Yield and Shift in younger children may exist because these children lack the cognitive skills to assess the interviewer's point of view (theory of mind) and 
respond in a strategic manner. The older children did not display any relation between Yield and Shift.

Theory of Mind and Suggestibility. In the examination of the relation between theory of mind and assent to misleading questions in an experienced event and a non-experienced event (suggestibility), the hypotheses were partially supported. In the full sample, theory of mind was significantly negatively related to suggestibility for an experienced event, but not a nonexperienced event. These findings are similar to Scullin and Bonner (2006) in that the negative relation was attained.

When age was controlled, the magnitude of the relation between pressured interview suggestibility for an experienced event and theory of mind decreased to non-significance. The magnitude of the relation was hypothesized to decrease because age accounts for a large portion of the variance in the relation between theory of mind and suggestibility. This finding was unlike the results of Scullin and Bonner (2006) in the full sample. The authors found that the positive relation between accuracy and theory of mind was still significant, even after controlling for age.

In the age-divided sample, further analysis revealed that in the older group, theory of mind was significantly negatively (and robustly) related to suggestibility in both an experienced event and a non-experienced event. Interestingly, this relation was not found in the younger group. Among children 54 months of age and older, a more developed theory of mind is related to fewer assents to misleading questions. Among older children (54 months of age and older), the relation between theory of mind and suggestibility in both an experienced event and a nonexperienced event was significant ( $r=-.44$ and $r=-.44$, respectively). When controlling for age in the older sample, the partial correlations yielded a significant negative relation between theory of mind and suggestibility in an experienced event and a non-experienced event $(r=-.45$ and $r=$ -.41 , respectively). These findings were analogous to the results in Scullin and Bonner's study, who found that after controlling for age, the relation between theory of mind and suggestibility in an experienced event remained significant (see Table 2). This finding suggests that age may not be as influential in the relation between theory of mind and suggestibility as children age across the preschool years, which further supports the premise that cognitive resources become more important across the preschool years. 
Examining the age group differences with the inaccurate shifts produced interesting results. In the experienced event interview, the younger age group did not display any significant correlations between the suggestibility variables and theory of mind and the proportion of inaccurate shifts. In the older age group, the proportion of inaccurate shifts in the experienced event interview was found to be strongly correlated with theory of mind. In the non-experienced event interview, the same pattern of results emerged with the correlation between the proportion of inaccurate shifts and theory of mind in the older age group becoming stronger. Above 54 months of age, theory of mind appears to be an individual difference in cognitive skill that can explain why some children shift answers due to some feedback from the interviewer, and why other children do not shift. In older children, the strong negative relation between theory of mind and inaccurate shifting, implies that as theory of mind skills increase, less inaccurate shifting in an experienced event or non-experienced event interview occurs (or a lack of theory of mind skills in older children is related to more inaccurate shifting). Since this relation was only found among the older children, this finding implies that theory of mind is related to suggestibility for children above 54 months of age. Thus, as shown in previous research, the age threshold of 54 months ("the magic number") is important in examining the construct validity of Shift and other suggestibility variables (Scullin et al., 2002).

Theory of Mind and the Predictive Ability of the VSSC. As noted by Scullin and Bonner (2006), recent developments in theory of mind research provide opportunities for further clarification of the relation between theory of mind and suggestibility and theory of mind as a predictor of suggestibility. In the regression analyses, as indicated by the significant models, the results showed that age, theory of mind, and Yield and Shift predicted assent to misleading questions about an experienced event, but not a non-experienced event (i.e., unrelated to the actual hypotheses). The results from this study cannot be directly compared to the multivariate predictions in Scullin and Bonner (2006) because of their inclusion of an executive function measure (i.e., inhibitory control) in the same step as theory of mind.

In addition, controlling for age, theory of mind, Shift, and the interactions, Yield was a significant unique predictor of suggestibility in an experienced event interview. This significant positive relation suggests that higher Yield scores are related to greater assent to misleading questions in an experienced event interview (more suggestibility). As found in Scullin and Ceci (2001), the tendency for children to Yield appears to be stable over the age span of 3- to 5-year- 
olds. This greater stability of Yield, compared with Shift, may be why Yield was found to be a significant unique predictor of assent to misleading questions, and not Shift. In addition, Yield is a measure of responding affirmatively to leading questions, and the dependent measure assessed was children's assent to misleading questions about an experienced event. Therefore, the relation between Yield and the outcome variable was not surprising.

The results from the hierarchical regression analyses involving the older children (54 months and older) showed that theory of mind was a significant predictor of suggestibility in an experienced event interview. In the final model (Step 3), controlling for age, Yield, and Shift, theory of mind was a robust significant unique predictor of assent to misleading questions in an experienced event interview. Also, Yield was a significant unique predictor of assent to misleading questions in an experienced event interview. Interestingly, theory of mind was a larger predictor in the older sample than in the full sample where theory of mind was not a significant predictor in Step 3. This pattern of results was not the same for the younger age group as none of the steps were significant. Previous studies have found a similar pattern of results in that a significant difference in cognitive abilities appears at the age of $4 \frac{1}{2}$ years. This finding adds to the literature that theory of mind becomes an increasingly robust predictor of pressured interview suggestibility for an experienced event across the preschool years, and is especially predictive for older preschool-age children.

In the older sample, further examination of the hierarchical regression analyses with a non-experienced event displayed a significant interaction between Yield and theory of mind in the final model (see Table 9). The strong, positive standardized beta coefficient suggests that Yield may be more predictive with a better developed theory of mind, or theory of mind may be more predictive with a stronger tendency to Yield to misleading questions in a non-experienced event interview.

Age differences in suggestibility have been consistently found, with young preschoolers being the most suggestible. Scullin and colleagues (2002) found minimal systematic relations between the VSSC and the dependent measures for children under $41 \frac{1}{2}$ years; however, suggestibility was predictable across situations for children over $4 \frac{1}{2}$ years. Theory of mind development has also been consistently found to relate to suggestibility, with young preschoolers having poorly developed theory of mind skills and being highly suggestible. Studying these 
individual differences in theory of mind and suggestibility are important because of the differences in cognition within age groups.

Limitations and Future Research. The size of the 5-year-old sample limits any conclusions that can be drawn about age differences. In addition, the unequal sample sizes of each age group may be problematic for future analyses. Future studies should obtain equivalent age group sizes, even if conducting correlational research, to aid in additional analytical support of the findings.

In addition, language skills should be examined with the use of the theory of mind scale. Children's language ability is closely linked to their ability to pass false belief tasks, as false belief is considered to be an indicator of mental state understanding (Slade \& Ruffman, 2005). The acquisition of theory of mind is primarily social in nature, and has been hypothesized to be mediated by three innate mechanisms involved in language development (i.e., pragmatics, semantic understanding, and syntax use; Garfield, Peterson, \& Perry, 2001).

Although language is a crucial element of successful theory of mind acquisition, Garfield, Peterson, and Perry (2001) state that proper theory of mind development is dependent upon social experience and language combined. For instance, the social nature of socioeconomic status indirectly influences the acquisition of theory of mind. Shatz, Diesendruck, Martinez-Beck, and Akar (2003) claim that there are indirect influences of language use on the accelerated cognitive development in children socialized in advantaged environments. Social-linguistically enriched environments form the basis of the relation found between false belief reasoning and language and false belief performance and SES.

Language skills may be crucial for passing certain tasks in the theory of mind scale, especially task 5, which appeared to be difficult for some children to understand. Task 5 involved a short story about a boy who was teased on a playground. Perhaps this task involved many words that children did not understand, or the plot of the short story may have been difficult to follow. Future studies should examine task 5, and should perhaps use an alternative task, as suggested by Wellman and Liu (2004).

The tasks in the theory of mind scale used in the present study all assess the understanding of false beliefs of other people. All 5 tasks in the progressive theory of mind scale ask the child to attend to another person's beliefs about an event, contents in a container, and emotions. Examining the differences between own false beliefs and another person's false beliefs 
can perhaps better define the relation between theory of mind and assent to misleading questions about a non-experienced (and an experienced) event. The differences in the types of theory of mind tasks used across studies may account for the differences in findings (Thomsen \& Berntsen, 2005). The examination of the use of multiple theory of mind tasks and their relation to suggestibility in multiple contexts should be examined further, and may provide explanations for the differing results in the literature.

Scullin and Bonner (2006) examined the use of an inhibitory control task as an executive function measure influencing the relation between suggestibility as measured by the VSSC and pressured interview suggestibility (inhibitory control was not examined in the current study). The researchers found a significant interaction between inhibitory control and Shift and stated that this interaction might reflect a qualitative change in Shift associated with the development of inhibitory control. The authors also mention that the attainment of a level of inhibitory control is important for the external validity of Shift in that Shift is a good predictor of performance in a pressured interview for children who pass the inhibitory control task.

Bruck and Melnyk (2004) state that one common theme in the findings in suggestibility research is that executive function and suggestibility are negatively correlated. Both executive functioning skills and accuracy involve maintaining the conceptualization of an original event and ignoring other misleading information that does not fit with the original memory of the event (inhibition). The relation between these two constructs is controversial due to conflicting significant findings and many nonsignificant findings. Bruck and Melnyk suggested that perhaps some of the nonsignificant findings emerged because of the young age of the samples and that older children should be used because older children are still in the process of executive function growth. In addition, the number of executive function tasks used in these studies, including Scullin and Bonner, was not diverse, usually only using one measure of inhibitory control. The use of multiple and diverse tasks may help clarify the relation between suggestibility as measured by the VSSC and pressured interview suggestibility (Zelazo, Müller, Frye, \& Marcovitch, 2003). In sum, the relation between suggestibility and executive functioning has not yet been thoroughly explored due to the multiple components of executive functioning. Future studies should examine more thoroughly the construct of executive function and its many components in conjunction with suggestibility. 
The findings relating to the strong age differences between children under 54 months of age and children 54 months and older suggest that further research should be done to investigate changes in cognitive abilities around this age. The strongest relationships were found among children 54 months of age and older, indicating that the VSSC may not have practical utility for children under 54 months of age. In addition, in the older age group, Yield and Shift were not correlated, unlike the younger age group. Older children may have a more sophisticated way of answering pressured interview questions and dealing with the demands of the interview situation. This phenomenon should be examined in future studies investigating children's strategies in answering pressured interview questions.

Researching individual differences in children's suggestibility is important for understanding the development of the construct. Changes in the ways children are suggestible during the preschool years may be related to underlying psychological factors like theory of mind. These cognitive mechanisms are important for understanding suggestibility due to the relations between the constructs. Understanding these mechanisms may be important in identifying children who may be prone to accepting suggestions in forensic or other interview situations, allowing the use of special precautions during interviews.

The recent surge of literature in the area of children's suggestibility has made the problems associated with interviewing children in a forensic situation apparent to investigators and others involved in the legal system. Untrained interviewers, who initially question the child, may be the first to uncover information. Therefore, the use of the VSSC for assessing children's tendency to be suggestible in a single, highly suggestive interview is important to investigate and is supported by the findings in this study for children over 54 months of age. 


\section{References}

Astington, J. W. (1993). The child's discovery of the mind. Cambridge, MA: Harvard University Press.

Astington, J.W., \& Jenkins, J.M. (1999). A longitudinal study of the relation between language and theory-of-mind development. Developmental Psychology, 35, 1311-1320.

Bloom, P., \& German, T.P. (2000). Two reasons to abandon the false belief task as a test of theory of mind. Cognition, 77, B25-B31.

Bruck, M., Ceci, S. J., \& Melnyk, L. (1997). External and internal sources of variation in the creation of false reports in children. Learning and Individual Differences, 9, 289-316.

Bruck, M., \& Melnyk, L. (2004). Individual differences in children's suggestibility: A review and synthesis. Applied Cognitive Psychology, 18, 947-996.

Carlson, S.M., Mandell, D.J., \& Williams, L. (2004). Executive function and theory of mind: Stability and prediction from ages 2 to 3. Developmental Psychology, 40, $1105-1122$.

Carlson, S. M., Moses, L. J., \& Claxton, L. J. (2004). Individual differences in executive functioning and theory of mind: An investigation of inhibitory control and planning ability. Journal of Experimental Child Psychology, 87, 299-314.

Ceci, S. J., \& Bruck, M. (1993). Suggestibility of the child witness: A historical review and synthesis. Psychological Bulletin, 113, 403-439.

Ceci, S. J., \& Bruck, M. (1995). Jeopardy in the courtroom: A scientific analysis of children's testimony. Washington, DC: American Psychological Association.

Ceci, S.J., \& Bruck, M. (1998). Children's testimony: Applied and basic issues. In W. Damon (Series Ed.), I.E. Sigel, \& K.A. Renninger, (Vol. Eds.), Handbook of Child Psychology: Vol.4. Child Psychology in Practice (5 ${ }^{\text {th }}$ ed., pp.713-774). New York: Wiley.

Chae, Y., Ceci, S.J. (2005). Individual differences in children's recall and suggestibility: The effect of intelligence, temperament, and self-perceptions. Applied Cognitive Psychology, 19, 383-407.

Cohen, J. (1988). Statistical power analysis for the behavioral sciences $\left(2^{\text {nd }}\right.$ ed.). Hillsdale, NJ: Lawrence Erlbaum Associates. 
Diamond, A., Kirkham, N., \& Amso, D. (2002). Conditions under which young children can hold two rules in mind and inhibit a prepotent response. Developmental Psychology, 38, 352-362.

Farrar, M.J., \& Goodman, G.S. (1992). Developmental changes in event memory. Child Development, 63, 173-187.

Garfield, J.L., Peterson, C.C., Perry, T. (2001). Social cognition, language acquisition and the development of the theory of mind. Mind and Language, 16, 494-541.

Garven, S., Wood, J. M., Malpass, R. S., \& Shaw, J. S. (1998). More than suggestion: the effect of interviewing techniques from the McMartin Preschool case. Journal of Applied Psychology, 83, 347-359.

Gopnik, A., \& Astington, J. W. (1988). Children's understanding of representational change and its relation to the understanding of false belief and the appearance reality distinction. Child Development, 59, 26-37.

Guajardo, N. R., \& Turley-Ames, K.J. (2004). Preschoolers' generation of different types of counterfactual statements and theory of mind understanding. CognitiveDevelopment, 19, 53-80.

Gudjonsson, G. H. (2003). The psychology of interrogations and confessions: A handbook. Chichester, UK: John Wiley \& Sons.

Gudjonsson, G. H. (1992) Interrogative suggestibility: Factor analysis of the Gudjonsson suggestibility scale. Personality and Individual Differences, 13, 479-481.

Gudjonsson, G. H. (1987). A parallel form of the Gudjonsson suggestibility scale. British Journal of Clinical Psychology, 26, 215-221.

Gudjonsson, G. H. (1987a). Historical background to suggestibility: How interrogative suggestibility differs from other types of suggestibility. Personality and Individual Differences, 8, 347-355.

Gudjonsson, G.H. (1984). A new scale of interrogative suggestibility. Personality and Individual Differences, 5, 303-314.

Hale, C.M., \& Tager-Flusberg, H. (2003). The influence of language on theory of mind: A training study. Developmental Science, 6, 346-359.

Halford, G.S., Mayberry, M.T., O’Hare, A.W., \& Grant, P. (1994). The development of memory and processing capacity. Child Development, 65, 1338-1356. 
Happe, F.G. (1994). Wechsler IQ profile and theory of mind in autism: A research note. Journal of Child Psychiatry, 35, 1461-1471.

Hughes, C. (1998). Finding your marbles: Does preschoolers' strategic behavior predict later understanding of mind? Developmental Psychology, 34, 1326-1339.

Loftus, E. F., \& Hoffman, H. G. (1989). Misinformation and memory: The creation of new memories. Journal of Experimental Psychology: General, 118, 100-104.

Lohmann, H., \& Tomasello, M. (2003). The role of language in development of false belief understanding: A training study. Child Development, 74, 1130-1144.

Memon, A., Walk, L., Bull, R., \& Koeknken, G. (1997). Isolating the effects of the cognitive interview techniques. British Journal of Psychology, 88, 179-198.

Perner, J., \& Lang, B. (1999). Development of theory of mind and executive control. Trends in Cognitive Sciences, 9, 337-344.

Perner, J., Lang, B., \& Kloo, D. (2002). Theory of mind and self-control: More than a common problem of inhibition. Child Development, 73, 752-757.

Powell, M.B., Jones, C.H., \& Campbell, C. (2003). A comparison of preschoolers' recall of experienced versus non-experienced events across multiple interviews. Applied Cognitive Psychology, 17, 935-952.

Quas, J. A., Qin, J, Schaaf, J. M., \& Goodman, G. S. (1997). Individual differences in children's and adults' suggestibility and false event memory. Learning and Individual Differences, 9, 359-390.

Quas, J. A., \& Schaaf, J. M. (2002). Children's memories of experienced and nonexperienced events following repeated interviews. Journal of Experimental Child Psychology, 83, 304-338.

Quas, J., Wallin, A. R., Papini, S. P., Lench, H., \& Scullin, M. H. (2005). Suggestibility, social support, and memory for a novel experience in young children. Journal of Experimental Child Psychology, 91, 315-341.

Reyna, V.F., \& Lloyd, F. (1997). Theories of false memory in children and adults. Learning and Individual Differences, 9, 95-123.

Scullin, M.H., \& Bonner, K. (2006). Theory of mind, inhibitory control, and preschool-age children's suggestibility in different interviewing contexts. Journal of Experimental Child Psychology, 93, 120-138. 
Scullin, M. H., \& Ceci, S. J. (2001). A suggestibility scale for children. Personality and Individual Differences, 30, 843-856.

Scullin, M. H., Kanaya, T., \& Ceci, S. J. (2002). Measurement of individual differences in children's suggestibility across situations. Journal of Experimental Psychology: Applied, 8, 233-246.

Shatz, M., Diesendruck, G., Martinez-Beck, I., \& Akar, D. (2003). The influence of language and socioeconomic status on children's understanding of false belief. Developmental Psychology, 39, 717-729.

Slade, L., \& Ruffman, T. (2005). How language does (and does not) relate to theory of mind: A longitudinal study of syntax, semantics, working memory and false belief. British Journal of Developmental Psychology, 23, 117-141.

Szarkowicz, D.L. Young children's false belief understanding during play. The Journal of Genetic Psychology, 160, 243-254.

Templeton, L. M., \& Wilcox, S. A. (2000). A tale of two representations: The misinformation effect and children's developing theory of mind. Child Development, 71, 402-416.

Thomsen, Y., \& Berntsen, D. (2005). Knowing that I didn't know: Preschoolers' understanding of their own false belief is a predictor of assents to fictitious events. Applied Cognitive Psychology, 19, 507-527.

Welch-Ross, M. K. (1999). Preschoolers' understanding of mind: Implications for suggestibility. Cognitive Development, 14, 101-131.

Welch-Ross, M. K., Diecidue, K., \& Miller, S. A. (1997). Young children's understanding of conflicting mental representation predicts suggestibility. Developmental Psychology, 33, $43-53$.

Wellman, H. M., Cross, D., \& Watson, J. (2001). Meta-analysis of theory-of-mind development: The truth about false belief. Child Development, 72, 655-684.

Wellman, H. M., \& Liu, D. (2004). Scaling theory-of-mind tasks. Child Development, 75, 523541.

Wimmer, H., \& Perner, J. (1983). Beliefs about beliefs: Representation and constraining function of wrong beliefs in young children's understanding of deception. Cognition, 13, 103-128. 
Yirmiya, N., Solomonica-Levi, D., Shulman, C., \& Pilowsky, T. (1996). Theory of mind abilities in individuals with autism, Down syndrome, and mental retardation of unknown etiology: The role of age and intelligence. Journal of Child Psychiatry, 37, 1003-1014.

Zelazo, P. D., Müller, U., Frye, D., \& Marcovitch, S. (2003). The development of executive function. Monographs of the Society for Research in Child Development, 68, 1-137. 


\section{Tables}

Table 1

Descriptive Statistics of Variables

\begin{tabular}{|c|c|c|c|c|}
\hline Variable $^{\mathrm{a}}$ & $M$ & $S D$ & Min & Max \\
\hline Age in months & 50.86 & 7.45 & 36 & 63 \\
\hline \multicolumn{5}{|l|}{ VSSC Scores } \\
\hline Memory Recall & 8.01 & 4.65 & 0 & 24 \\
\hline Yield & 7.08 & 3.73 & 0 & 14 \\
\hline Shift & 5.34 & 3.34 & 0 & 16 \\
\hline Total Suggestibility & 12.42 & 4.15 & 3 & 25 \\
\hline Theory of Mind & 2.58 & 1.20 & 0 & 5 \\
\hline \multicolumn{5}{|l|}{ Magic Interview } \\
\hline Accurate Questions & 3.46 & 1.08 & 1 & 5 \\
\hline Misleading Questions & 2.99 & 1.84 & 0 & 5 \\
\hline Proportion Inaccurate Shifts ${ }^{b}$ & .39 & .42 & 0 & 1 \\
\hline \multicolumn{5}{|l|}{ Monkey Interview } \\
\hline Misleading Questions & 7.62 & 2.95 & 0 & 10 \\
\hline Proportion Inaccurate Shifts ${ }^{c}$ & .44 & .42 & 0 & 1 \\
\hline
\end{tabular}

Note. ${ }^{a} \mathrm{~N}=91 .{ }^{b} \mathrm{n}=78$. These children were excluded from analyses for the magic show interview because they responded affirmatively to every question in the interview. ${ }^{c} n=77$. These children were excluded from analyses for the monkey interview because they responded affirmatively to every question in the interview. 
Table 2

Pearson Correlations Between the Variables

\begin{tabular}{|c|c|c|c|c|c|c|c|c|c|c|}
\hline Variable & 2 & 3 & 4 & 5 & 6 & 7 & 8 & 9 & 10 & 11 \\
\hline 1. Age in months & $.36^{* *}$ & $-.40 * *$ & .04 & $-.33 * *$ & $.49^{* *}$ & $-.25 * *$ & -.03 & $.30^{* *}$ & -.02 & .09 \\
\hline 2. Memory Recall & -- & -.19 & .08 & -.11 & $.26^{*}$ & $-.22 *$ & .05 & $.25^{*}$ & -.13 & -.07 \\
\hline 3. Yield & & -- & $.31^{* *}$ & $.65^{* *}$ & $-.26 * *$ & $.29^{* *}$ & .12 & -.14 & .16 & .05 \\
\hline 4. Shift & & & -- & $.51 * *$ & .03 & .08 & .02 & .10 & .13 & -.12 \\
\hline 5. Total Suggestibility & & & & -- & $-.21^{*}$ & $.32 * *$ & .13 & -.05 & $.24^{*}$ & -.05 \\
\hline 6. Theory of Mind & & & & & -- & $\begin{array}{l}-.30^{* *} \\
(-.21)\end{array}$ & $\begin{array}{c}-.14 \\
(-.14)\end{array}$ & .19 & -.18 & -.02 \\
\hline 7. Misleading Magic & & & & & & -- & $.62^{* *}$ & .05 & $.91 * *$ & $.45^{* *}$ \\
\hline 8. Misleading Monkey & & & & & & & -- & $.23 *$ & $.57 * *$ & $.72 * *$ \\
\hline 9. Magic Interview Accurate Questions & & & & & & & & -- & .20 & .12 \\
\hline 10. Proportion Inaccurate Shifts - Magic & & & & & & & & & -- & .16 \\
\hline 11. Proportion Inaccurate Shifts - Monkey & & & & & & & & & & -- \\
\hline
\end{tabular}

Note. Values in parentheses are partial correlations controlling for age in months.

$N=91$.

${ }^{*} p<.05 * * p<.01$ (2-tailed). 
Table 3

Summary of Hierarchical Regression Analyses Predicting Assents to Misleading Questions about an Experienced Event $(N=91)$

\begin{tabular}{|c|c|c|c|c|}
\hline Variable & $b$ & $S E b$ & $t$ & $\beta$ \\
\hline \multicolumn{5}{|l|}{ Step 1} \\
\hline Age & $-.06 *$ & .03 & -2.39 & -.25 \\
\hline \multicolumn{5}{|l|}{ Step 2} \\
\hline Age & -.03 & .03 & -1.14 & -.13 \\
\hline Theory of Mind & $-.36^{*}$ & .18 & -2.02 & -.23 \\
\hline \multicolumn{5}{|l|}{ Step 3} \\
\hline Age & -.01 & .03 & -.34 & -.04 \\
\hline Theory of Mind & -.32 & .17 & -1.87 & -.21 \\
\hline Yield & $.13^{*}$ & .06 & 2.37 & .27 \\
\hline Shift & .09 & .06 & 1.59 & .17 \\
\hline \multicolumn{5}{|l|}{ Step 4} \\
\hline Age & -.06 & .03 & -.22 & -.03 \\
\hline Theory of Mind & $-.37 *$ & .17 & -2.12 & -.24 \\
\hline Yield & $.13^{*}$ & .06 & 2.39 & .27 \\
\hline Shift & .09 & .06 & 1.58 & .16 \\
\hline Theory of Mind x Yield & .04 & .04 & .90 & .10 \\
\hline Theory of Mind $\mathrm{x}$ Shift & .10 & .05 & 1.91 & .20 \\
\hline
\end{tabular}

Note. $R^{2}=.06$ for Step $1 ; \Delta R^{2}=.04$ for Step $2 ; \Delta R^{2}=.06$ for Step $3 ; \Delta R^{2}=.04$ for Step $4(p \mathrm{~s}<.05)$. Full Model $R^{2}=.20$. Final $R^{2}=.16($ Step 3$)$.

$* p<.05$. 
Table 4

Summary of Hierarchical Regression Analyses Predicting Assents to Misleading Questions about a Non-Experienced Event $(N=91)$

\begin{tabular}{|c|c|c|c|c|}
\hline Variable & $b$ & $S E b$ & $t$ & $\beta$ \\
\hline \multicolumn{5}{|l|}{ Step 1} \\
\hline Age & -.01 & .04 & -.24 & -.03 \\
\hline \multicolumn{5}{|l|}{ Step 2} \\
\hline Age & .02 & .05 & .45 & .05 \\
\hline Theory of Mind & -.40 & .30 & -1.35 & -.16 \\
\hline \multicolumn{5}{|l|}{ Step 3} \\
\hline Age & .04 & .05 & .81 & .10 \\
\hline Theory of Mind & -.37 & .30 & -1.24 & -.15 \\
\hline Yield & .11 & .10 & 1.18 & .15 \\
\hline Shift & .06 & .10 & .60 & .07 \\
\hline \multicolumn{5}{|l|}{ Step 4} \\
\hline Age & .06 & .05 & 1.10 & .14 \\
\hline Theory of Mind & -.46 & .30 & -1.55 & -.19 \\
\hline Yield & .12 & .10 & 1.28 & .16 \\
\hline Shift & .06 & .10 & .61 & .07 \\
\hline Theory of Mind x Yield & .13 & .07 & 1.79 & .21 \\
\hline Theory of Mind x Shift & .10 & .09 & 1.18 & .13 \\
\hline
\end{tabular}

Note. $R^{2}=.00$ for Step $1 ; \Delta R^{2}=.02$ for Step $2 ; \Delta R^{2}=.02$ for Step $3 ; \Delta R^{2}=.04$ for Step 4. Final $R^{2}=.08$. 
Table 5

Descriptive Statistics of Variables by Group

\begin{tabular}{|c|c|c|c|c|c|c|c|c|}
\hline Variable & $N$ & $M$ & $S D$ & Range & $N$ & $M$ & $S D$ & Range \\
\hline & \multicolumn{7}{|c|}{$\underline{\text { Age Groups }}$} & \\
\hline & \multicolumn{4}{|c|}{ Older } & \multicolumn{4}{|c|}{ Younger } \\
\hline Age in months & 39 & $58.03 * *$ & 2.81 & $54-63$ & 52 & $45.48^{* *}$ & 4.81 & $36-53$ \\
\hline Memory Recall & 39 & $7.38^{*}$ & 4.16 & $1-17$ & 52 & $8.48^{*}$ & 5.00 & $0-24$ \\
\hline Yield & 39 & $5.51^{* *}$ & 3.05 & $0-13$ & 52 & $8.25^{* *}$ & 3.78 & $1-14$ \\
\hline Shift & 39 & 5.31 & 2.96 & $0-11$ & 52 & 5.37 & 3.63 & $0-16$ \\
\hline Total Suggestibility & 39 & $10.82^{* *}$ & 3.63 & $3-17$ & 52 & $13.62 * *$ & 4.15 & $4-25$ \\
\hline Theory of Mind & 39 & $3.08^{* *}$ & 1.20 & $0-5$ & 52 & $2.21 * *$ & 1.07 & $0-5$ \\
\hline Misleading Magic & 39 & $2.38^{*}$ & 1.87 & $0-5$ & 52 & $3.44^{*}$ & 1.70 & $0-5$ \\
\hline Misleading Monkey & 39 & 7.54 & 3.08 & $0-10$ & 52 & 7.67 & 2.88 & $0-10$ \\
\hline Proportion Shifts Magic & 38 & $.37^{* *}$ & .40 & $0-1$ & 40 & $.41^{* *}$ & .43 & $0-1$ \\
\hline Proportion Shifts Monkey & 31 & $.47^{* *}$ & .43 & $0-1$ & 46 & $.41^{* *}$ & .42 & $0-1$ \\
\hline
\end{tabular}

Note. ${ }^{*} p<.05 * * p<.01$. 
Table 6

Pearson Correlations Between the Variables with Older Children $(N=39)$

\begin{tabular}{|c|c|c|c|c|c|c|c|c|}
\hline Variable & 2 & 3 & 4 & 5 & 6 & 7 & 8 & 9 \\
\hline 1. Age in months & -.30 & .11 & -.16 & $.40^{*}$ & -.06 & -.18 & -.05 & -.12 \\
\hline 2. Yield & -- & -.27 & $\begin{array}{l}.62^{* *} \\
(.61)\end{array}$ & -.15 & .31 & .30 & .26 & .07 \\
\hline 3. Shift & & -- & $\begin{array}{l}.59 * * \\
(.62)\end{array}$ & .05 & .05 & -.00 & .09 & .01 \\
\hline \multicolumn{3}{|l|}{ 4. Total Suggestibility } & -- & -.09 & .30 & .25 & .29 & .07 \\
\hline \multicolumn{3}{|l|}{ 5. Theory of Mind } & & -- & $\begin{array}{l}-.44 * * \\
(-.45)\end{array}$ & $\begin{array}{l}-.44^{* *} \\
(-.41)\end{array}$ & $-.37 *$ & $-.50 * *$ \\
\hline \multicolumn{3}{|l|}{ 6. Misleading Magic } & & & -- & $\begin{array}{l}.59 * * \\
(.59)\end{array}$ & $.95^{* *}$ & $.56^{* *}$ \\
\hline \multicolumn{3}{|l|}{ 7. Misleading Monkey } & & & & -- & $.55^{* *}$ & $.82 * *$ \\
\hline \multicolumn{4}{|c|}{ 8. Prop. Inaccurate Shifts - Magic } & & & & -- & -.12 \\
\hline \multicolumn{4}{|c|}{ 9. Prop. Inaccurate Shifts - Monkey } & & & & & -- \\
\hline
\end{tabular}

Note. Values in parentheses are partial correlations controlling for age in months. $N=39$ except for proportion inaccurate shifts for the magic interview, where $N=38$, and except for proportion inaccurate shift for the monkey interview, where $N=31$.

${ }^{*} p<.05 * * p<.01$ (2-tailed). 
Table 7

Pearson Correlations Between the Variables with Younger Children $(N=52)$

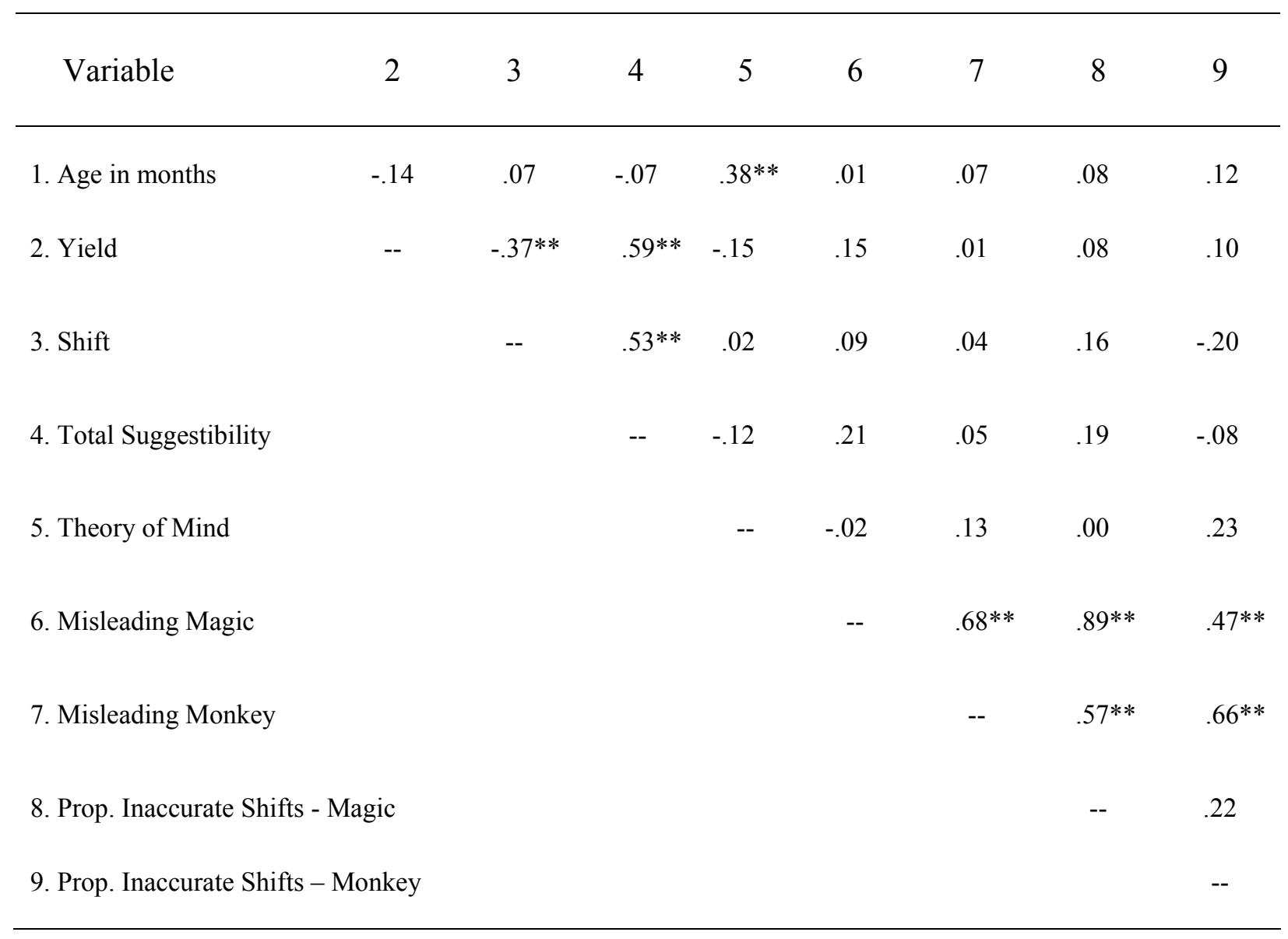

Note. $N=52$ except for proportion inaccurate shifts for the magic interview, where $N=40$, and except for proportion inaccurate shifts for the monkey interview, where $N=46$.

$* * p<.01$ (2-tailed). 
Table 8

Summary of Hierarchical Regression Analyses Predicting Assents to Misleading Questions about an Experienced Event with Older Children $(N=39)$

\begin{tabular}{|c|c|c|c|c|}
\hline Variable & $b$ & $S E b$ & $t$ & $\beta$ \\
\hline \multicolumn{5}{|l|}{ Step 1} \\
\hline Age & -.04 & .11 & -.35 & -.06 \\
\hline \multicolumn{5}{|l|}{ Step 2} \\
\hline Age & .09 & .11 & .88 & .14 \\
\hline Theory of Mind & $-.77 * *$ & .25 & -3.03 & -.49 \\
\hline \multicolumn{5}{|l|}{ Step 3} \\
\hline Age & .15 & .11 & 1.34 & .23 \\
\hline Theory of Mind & $-.75 * *$ & .24 & -3.09 & -.48 \\
\hline Yield & $.21^{*}$ & .10 & 2.21 & .34 \\
\hline Shift & .09 & .09 & .97 & .14 \\
\hline \multicolumn{5}{|l|}{ Step 4} \\
\hline Age & .17 & .11 & 1.53 & .26 \\
\hline Theory of Mind & $-.72 * *$ & .25 & -2.92 & -.46 \\
\hline Yield & .13 & .12 & 1.14 & .22 \\
\hline Shift & .03 & .11 & .24 & .04 \\
\hline Theory of Mind x Yield & .11 & .10 & 1.07 & .22 \\
\hline Theory of Mind x Shift & .09 & .09 & 1.03 & .19 \\
\hline
\end{tabular}

Note. $R^{2}=.003$ for Step $1 ; \Delta R^{2}=.20$ for Step $2 ; \Delta R^{2}=.10$ for Step $3 ; \Delta R^{2}=.04$ for Step $4(p \mathrm{~s}<.05)$. Full Model $R^{2}=.34$. Final $R^{2}=.31($ Step 3$)$.

${ }^{*} p<.05 * * p<.01$. 
Table 9

Summary of Hierarchical Regression Analyses Predicting Assents to Misleading Questions about a Non-Experienced Event with Older Children $(N=39)$

\begin{tabular}{|c|c|c|c|c|}
\hline Variable & $b$ & $S E b$ & $t$ & $\beta$ \\
\hline \multicolumn{5}{|l|}{ Step 1} \\
\hline Age & -.20 & .18 & -1.12 & -.18 \\
\hline \multicolumn{5}{|l|}{ Step 2} \\
\hline Age & -.04 & .18 & -.03 & -.00 \\
\hline Theory of Mind & $-1.12 *$ & .42 & -2.67 & -.44 \\
\hline \multicolumn{5}{|l|}{ Step 3} \\
\hline Age & .07 & .18 & .39 & .07 \\
\hline Theory of Mind & $-1.10 *$ & .41 & -2.65 & -.43 \\
\hline Yield & .28 & .16 & 1.71 & .27 \\
\hline Shift & .09 & .16 & .53 & .08 \\
\hline \multicolumn{5}{|l|}{ Step 4} \\
\hline Age & .17 & .18 & .97 & .16 \\
\hline Theory of Mind & $-.99 *$ & .39 & -2.51 & -.39 \\
\hline Yield & .03 & .19 & .02 & .00 \\
\hline Shift & .02 & .18 & .12 & .02 \\
\hline Theory of Mind x Yield & $.39 *$ & .16 & 2.47 & .49 \\
\hline Theory of Mind x Shift & .09 & .14 & .65 & .11 \\
\hline
\end{tabular}

Note. $R^{2}=.03$ for Step $1 ; \Delta R^{2}=.16$ for Step $2 ; \Delta R^{2}=.06$ for Step $3 ; \Delta R^{2}=.12$ for Step $4(p \mathrm{~s}<.05)$.

Final $R^{2}=.38$.

$* p<.05$. 
Appendices

Appendix A

Theory of Mind Scale (Wellman and Liu, 2004)

Task 1. Diverse Desires Children are shown a toy figure and are also shown a sheet of paper with a carrot and a cookie drawn on it. The children are asked, "Here is Mr. Jones. Mr. Jones wants a snack because it is snack time. Which snack would you like best: a carrot or a cookie?" This question is the own-desire question. Depending on which snack the child chooses, the response can follow (if the carrot is chosen): "That's a good choice, but Mr. Jones really likes cookies. He doesn't like carrots. So, now it's time to eat. Which snack will Mr. Jones choose?" This question is considered the target question, and must be answered in opposition to the owndesire question.

Task 2. Diverse Beliefs Children are shown a toy figure and a sheet of paper with some bushes and a garage drawn on it. The children are asked, "Here is Linda. Linda needs to find her cat and her cat might be in the bushes or in the garage. Where do you think the cat is?" This question is the own-belief question. If the child picks the bushes, the child is then asked, "That's a good idea, but Linda thinks that her cat is in the garage. Where will Linda look for her cat?" This question is the target question, and to pass this task, the child must answer opposite from the own-belief question.

Task 3. Knowledge Access Children are shown a plastic box with a drawer that holds a small toy dog inside the drawer. The children are asked, "Here is a drawer. What do you think is inside the drawer?" The children can give any response that they like, or say that they do not know. The drawer is then opened to reveal the dog. The drawer is closed again. The children are asked again, "What is in the drawer?" Next, a toy figure is produced and the children are asked, "This is Polly. Polly has never seen inside the drawer. Here comes Polly. Does Polly know what is inside the drawer?" This question is the target question. Then, the children are asked, "Did Polly see inside the drawer?" This question is the memory or knowledge question. Both questions must be answered "no" to pass this task.

Task 4. Contents False Belief The children encounter a clearly labeled Band-Aid box with a plastic toy pig inside the closed box. The children are asked, "Here is a Band-Aid box. What do you think is inside the box?" Then the box is opened to reveal the pig. The box is then closed again. The children are asked again what is inside the box. Next, a toy figure is 
produced. The children are asked, "This is Peter. Peter has never seen inside the box. Now, here comes Peter. What does Peter think is inside the box?" This question is the target question. Next, the children are asked a memory question, "Did Peter see inside the box?" To pass this task, the children must answer "Band-Aids" for the first question, and "no" for the second question.

Task 5. Real-Apparent Emotion First, children are shown a sheet of paper with three faces drawn on it - a happy face, a neutral face, and a sad face. This paper is used to check if the children can identify the expressions by pointing to the correct face when asked. The children are shown a cardboard cutout of a figure, but are shown the back of the cutout so the children cannot see the facial expression of the cutout. The children are told, "This story is about a boy. I am going to ask you about how the boy really feels inside and how the boy looks on his face. He might really feel one way inside, but look a different way on his face. Or, the boy may feel the same way he feels inside and how he looks on his face. I want you to tell me how he really feels inside and how he looks on his face. This story is about Matt. Matt's friends were all playing together and telling jokes. One of the children, Rosie, told a mean joke about Matt and everyone laughed. Everyone thought it was funny, but Matt did not think that it was funny. Matt did not want the other children to see how he felt because they would call him a baby. So, Matt tried to hide how he felt. What did the other children do when Rosie told the mean joke? And what would the other children do if they knew how Matt felt?" Displaying the three pictures of the faces, the children are asked, "How did Matt really feel when everyone laughed? This question is the target-feel question. "How did Matt try to look on his face when everyone laughed?" This question is the target-look question. To pass this task, the children must answer the target-feel question more negatively than the target-look question (a more negative emotion). 


\section{Appendix B}

The Magic Show Interview: Experienced Event

Experienced Event Set-up. The magician was a trainee and wore a black cape and a hat. The magician was a male and had dark hair. The magician tried to make a peanut butter sandwich appear but got broccoli instead. The magician made colors magically appear in a coloring book. He made carrots appear for a bunny and guessed the correct color of the crayon a child selected from a box of crayons. The magician told a secret and said not to tell anyone. Also, the magician had a letter on a necklace around his neck.

\section{The Interview}

"I want to ask you some questions about the other day when the trainee magician came and did a magic show for you. He had a black cape, didn't he?"

"Well, I already talked to some of the kids and they said that the magician did some really interesting things. I want to see if you have a good memory like those other kids. Do you have a good memory?"

If "yes" - "Good! Because I really need your help."

If "no" - "Well, try as hard as you can because the other kids all did a really good job of remembering what the magician did."

1. The other kids said the magician tried to make a peanut butter sandwich appear but got something else instead. Did the magician try to make a peanut butter sandwich appear but got something else instead? (Accurate)

Yes

No

DK Other

If "yes" - "What a super job you are doing! What did the magician get instead of a peanut butter sandwich? Go to next question

If "no" - "Think really hard. The other kids say she did. Did the magician try to make a peanut butter sandwich appear, but got something else instead?"

Yes No DK Other

If "yes" - "What a super job you are doing! What did the magician get instead of a peanut butter sandwich? Go to next question

If "no" - "Okay, we'll try the next question." Go to next question 
2. The other kids said the magician tried to turn water into orange juice, but by accident turned water into milk. Did the magician accidentally turn water into milk? (Misleading) Repeat follow-up questions as in question 1

3. The other kids say that the magician told them a secret and said not to tell anyone. Did the magician tell you a secret and tell you not to tell anyone? (Accurate) Repeat follow-up questions as in question 1

4. The other kids said the magician hugged each of them as they left the room. Did the magician hug each of the kids? (Misleading) Repeat follow-up questions as in question 1

5. The other kids said the magician had a letter on a necklace around his neck. Did the magician have a letter around his neck? (Accurate) Repeat follow-up questions as in question 1

6. The other kids said that the magician turned some carrots into something else. Did the magician turn carrots into something else? (Misleading) Repeat follow-up questions as in question 1

7. The other kids said the magician made something appear for his bunny. Did the magician make something appear for his bunny? (Accurate) Repeat follow-up questions as in question 1

8. The other kids said that the magician pulled something out of a hat. Did the magician pull something out of a hat? (Accurate) Repeat follow-up questions as in question 1

9. The other kids said the magician took the kids on a balloon ride outside. Did the magician take the kids on a balloon ride? (Misleading) Repeat follow-up questions as in question 1

10. The other kids said the magician took you kids to a farm. Did the magician take you kids to a farm? (Misleading) Repeat follow-up questions as in question 1 


\section{The Lost Monkey Interview: The Non-Experienced Event}

Non-Experienced Event Set-up. A lady was on the playground and had lost her monkey. She approached a group of children and asked the children to help her find the monkey. The monkey's name was George. George was under a tree. When George was found, she gave all the kids hugs for helping her find George.

\section{The Interview}

"You know what? I heard that last week there were a whole bunch of you on the playground and you helped a lady on the playground find a monkey? She was wearing glasses and a green sweater, wasn't she?"

"Well, I already talked to some of the kids and they remember helping the lady find the monkey. I want to see if you have a good memory like those other kids. Do you have a good memory?"

If "yes" - "Good! Because I really need your help."

If "no" - "Well, try as hard as you can because the other kids all did a really good job of remembering what the lady did."

1. The other kids said that the lady read them a story before you helped her find her monkey? Did the lady read you a story?

Yes_ No__ DK__ Other If "yes" - "What a super job you are doing! What did the lady read you a story about? Go to next question

If "no" - "Think really hard. The other kids say she did. Did the lady read you a story before you helped her find her monkey?"

Yes No DK Other

If "yes" - "What a super job you are doing! What did the lady read you're a story about? Go to next question

If "no" - "Okay, we'll try the next question." Go to next question 
2. The other kids said that the lady came up to them and told them that she hid her monkey, and she asked them to help her find the monkey. So they walked around the playground looking all over for the monkey. Did the lady and the kids look for the monkey in the playground? Repeat follow-up questions as in question 1

3. The other kids say that the lady told them a secret about the monkey and said not to tell anyone. Did the lady tell you a secret about the monkey and tell you not to tell anyone? Repeat follow-up questions as in question 1

4. The other kids said the lady hugged each of you for helping her. Did the lady hug each of you? Repeat follow-up questions as in question 1

5. The other kids said the lady had on a necklace made of flowers around her neck. Did the lady have flowers around her neck? Repeat follow-up questions as in question 1

6. The other kids said that you found her monkey George under a tree. Did you find George under a tree? Repeat follow-up questions as in question 1

7. The other kids said that the monkey had a leash. They told me that you were the one who helped the lady put a leash on the monkey! Did you help put the leash on the monkey? Repeat follow-up questions as in question 1

8. The other kids said that the lady put George into a cage. Did the lady put George into a cage? Repeat follow-up questions as in question 1

9. The other kids said the lady took the kids on an airplane ride. Did the lady take the kids on an airplane ride? Repeat follow-up questions as in question 1

10. The other kids said the lady took you kids to visit a clown at the mall. Did the lady take you kids to visit a clown at the mall? Repeat follow-up questions as in question 1 
Appendix C

\section{TURN ON CAMERA Interview 1 TURN ON CAMERA}

The Video Suggestibility Scale for Children

For videotaping purposes, say child's name while building rapport.

Open-ended questions

A. Do you remember that video about the birthday party? Tell me everything you remember about the birthday party.

Repeatedly probe: What else do you remember?

When the child finishes responding, ask:

B. Tell me, who was at the birthday party? For each character from the list of characters that the child generates AND for any characters mentioned above in the open-ended questioning, ask the child the 2 questions below:

B1a. What did look like?

B1b. What was he/she wearing?

B2a. What did look like?

B2b. What was he/she wearing?

B3a. What did look like?

B3b. What was he/she wearing? 
C. Continue asking about characters generated by the child and conclude by asking: Who else was at the birthday party?

C1a. What did look like?

C1b. What was he/she wearing?

C2a. What did look like?

C2b. What was he/she wearing?

D. What happened when the children opened the presents?

E. Did anything kind of scary happen during the birthday party?

F. What was your favorite part of the video? 
1. Did the two girls arrive at the party in a bright red car?

Round 1: YES NO DON'T KNOW NO RESPONSE DON'T KNOW NO RESPONSE OTHER Round 2: YES $\mathrm{NO}$ OTHER

2. Was there a girl named Suzie at the party?

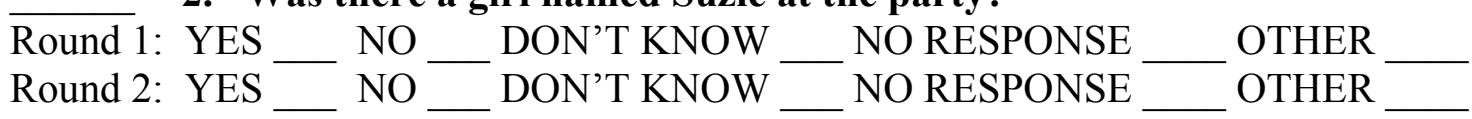

3. Was there a little white doggie at the party?

Round 1: YES

Round 2: YES NO _ DON'T KNOW NO RESPONSE DON'T KNOW NO RESPONSE OTHER OTHER

4. Did that clumsy girl Robin knock over the lamp?

Round 1: YES NO _ DON'T KNOW NO RESPONSE

Round 2: YES NO__ DON'T KNOW NO RESPONSE OTHER OTHER

5. Did the kids break a balloon while they were hitting them around?

Round 1: YES $\mathrm{NO}$ DON'T KNOW NO RESPONSE Round 2: YES NO_ DON'T KNOW NO RESPONSE OTHER OTHER

6. Did Robin trip and fall on the way to the table?

Round 1: YES NO__ DON'T KNOW NO RESPONSE Round 2: YES NO_ DON'T KNOW NO RESPONSE OTHER OTHER

7. When the clown juggled, did he drop a ball?

Round 1: YES $\mathrm{NO}$ DON'T KNOW NO RESPONSE DON'T KNOW NO RESPONSE OTHER Round 2: YES NO OTHER

8. Was Billy going to bring his new football to school the next day? Round 1: YES $\mathrm{NO}$ DON'T KNOW NO RESPONSE Round 2: YES $\mathrm{NO}$ DON'T KNOW NO RESPONSE OTHER

9. Was one of Billy's birthday presents broken when he opened it?

Round 1: YES Round 2: YES NO DON'T KNOW DON'T KNOW NO RESPONSE NO RESPONSE OTHER OTHER

Feedback

You missed a few of the questions.

Let's go through them again and see if you can do better this time. 
10. Did Billy break the toy?

Round 1: YES NO DON'T KNOW NO RESPONSE NO RESPONSE

OTHER Round 2: YES NO DON'T KNOW OTHER

11. Did Billy and his friends play with the broken toy after Billy's dad fixed it?

Round 1: YES NO DON'T KNOW NO RESPONSE NO RESPONSE OTHER Round 2: YES NO__ DON'T KNOW OTHER

12. Did Billy's dad cut the birthday cake?

Round 1: YES Round 2: YES NO DON'T KNOW NO RESPONSE NO RESPONSE OTHER OTHER

13. When Robin dropped the cake on her lap, did she just go ahead and eat it?

Round 1: YES $\mathrm{NO}$ DON'T KNOW NO RESPONSE NO RESPONSE OTHER Round 2: YES $\mathrm{NO}$ DON'T KNOW OTHER

14. When Billy spilled his juice, did he cry?

Round 1: YES Round 2: YES $\mathrm{NO}$ DON'T KNOW NO RESPONSE NO RESPONSE OTHER NO__ DON'T KNOW OTHER

15. Did Billy get the last piece of cake?

Round 1: YES Round 2: YES NO DON'T KNOW NO RESPONSE NO _ DON'T KNOW _ NO RESPONSE NO _ DON'T KNOW _ NO RESPONSE OTHER OTHER

16. Did Billy's dad tell the kids that there wasn't a real fire?

Round 1: YES $\mathrm{NO}$ DON'T KNOW NO RESPONSE

Round 2: YES NO_ DON'T KNOW NO RESPONSE OTHER OTHER

17. Did Billy feel "all grown up" now that he was five years old?

Round 1: YES Round 2: YES $\mathrm{NO}$ DON'T KNOW NO RESPONSE NO RESPONSE OTHER NO_ DON'T KNOW NORPONSE OTHER

\section{Did Billy's friends stay overnight?}

Round 1: YES NO DON'T KNOW NO RESPONSE Round 2: YES $\mathrm{NO}$ DON'T KNOW NO RESPONSE OTHER OTHER

\section{Feedback}

You missed some of the questions again.

Let's go through them one more time and see if you can do better this time. 


\section{Appendix D}

\section{The Magic Show Script}

Children were brought into the room and sat in front of the magician and his table.

\section{Magician Introduction}

Hello boys and girls! My name is Matthew Bogart Scullin II, "The Great Deceiver of Children's Minds." Do you know what I am? Yes, a magician. Well sort of. I'm actually a trainee magician. Who can tell me what the word trainee means? Yes, it means someone who is learning to be something. If you were learning how to play football you'd be called a trainee football player. If you were learning to sing, you'd be a trainee singer. Well I'm a trainee magician. I'm learning to be a magician. That's why I've got this big L round my neck. Thank you, children, for letting me come here to do my show today.

\section{Magician Establishes Children's Role}

Because I'm learning to be a magician, I need you to help me by telling me what you think of my show. If you don't like some of the tricks, then I might need to practice them a bit more or learn how to do another trick. So it would be a big help to me if you told me what you think.

Magician shows the children the different audience ratings:

$\begin{array}{lll}\text { Thumbs Down } & = & \text { Bad Job } \\ \text { Two Finger Clap } & = & \text { OK } \\ \text { Hand on Thigh } & = & \text { Good } \\ \text { Normal Clap } & = & \text { Very Good } \\ \text { Loud Clap } & = & \text { Excellent, Terrific, Smashing }\end{array}$

\section{Magician Chooses A Helper}

One more thing, I will need a helper for some of the tricks.

The helper stays sitting down with the others and only comes up when called.

\section{Magician Explains Clothing}

Before we start the magic show, I'd like to tell you a bit about my magic outfit. First, this is my magic hat. This is where all my ideas for the magic tricks come from and it's great for keeping things in too, like little white bunny rabbits. Unfortunately, bunny wasn't feeling well and had to stay home today.

Next up is the cape. What color is it? Yes, black. I find black terribly boring. I would like to have a bright red or a bright pink cape. But magicians are supposed to wear only black capes, so I'm wearing a black cape. 
Finally, I have the very special white magic gloves. These are the most important part of the magician's outfit. The gloves give magicians special powers and without them, none of the tricks would work. It's important not to wash them. The gloves don't do it all for you though. Magicians still have to practice the tricks to get good at them.

If you're not a very good magician and you're just a trainee like me, there are other things that you can use to help do the tricks. Do you know what other things help magicians to do magic?

The first is a magic wand. Some really good magicians don't need a magic wand, but if you're just a beginner like me, then it helps you to do the tricks because the magic wand has special powers. I got this at the magic shop just for magicians. They told me that I've got to point the wand at the object or it won't work. Like if I wanted to make a rabbit appear in my hat, I'd have to point the wand at my hat. Can you make sure I point my wand at the trick when I do it? Thank you, because I forget.

\section{Magician and Magic Bag Trick}

You know, I was in a bit of a rush this morning, and didn't have time for breakfast and now I'm really hungry. Can you hear my stomach rumbling? I could have ordered something at McDonald's, but I didn't need to. Do you know why? Because I'm a magician, and magicians can make food appear out of thin air.

Magicians have a special magic bag that makes any food that they want appear. Look, it's a pretty bag isn't it? Imagine your mom or dad trying to fit all their groceries in this bag. Well magicians don't need a bigger bag because you're only allowed to ask for one thing to appear at a time. The trick doesn't work if you ask for too many things at once. Can you tell me the color of the magic food bag? Yes it's red. They can't be plastic or string. If it wasn't made out of this special red material, then the trick wouldn't work. Do you know where we get the special red material? Yes, from the magic shop for magicians. The magic shop has all the stuff that magicians need and there are people in there to help trainee magicians like me to learn the tricks.

All I have to do is say some magic words, wave the wand and any food I want appears in the bag, provided of course I only ask for one thing, say the right spell and point the wand at the bag. Do you want me to try it? Okay, first lets check that there aren't any baked beans in here.

Magician turns bag inside out, unzips bag and puts hand through opening.

I had baked beans for my dinner last night, and I wouldn't want any to be left inside here. Nope, it's clean. Okay what would I like? I know, I think I'd really like a peanut butter and jelly sandwich. That'd be good. Would you all repeat the magic words with me while I wave the magic wand. The magic words are: Alakazam!,Alakapow! Make me a peanut butter and jelly sandwich and make it now.

The children and magician say the spell while the magician waves the wand and points it at the bag. 
Let me have a look. Oh no!!! The trick didn't work properly. I didn't get a jam sandwich, I got broccoli!

Magician shows the children the broccoli.

Where is my jam sandwich? Perhaps I should say "Please" next time. Sometimes magicians forget to say please and if they don't say please, the tricks might not work. I keep forgetting these things. So many things to remember.

Okay, what did you think of that trick? I think I need to practice it a bit more, don't you? But I'm trying to be a good magician. I'm not too bad am I?

\section{Magician Performs the Carrot Trick}

Well, I'm not going to eat the broccoli. It's not cooked. I really need to get some food for bunny, though. What could I have? Any suggestions? I know, I have some carrots somewhere around here. Someone gave them to me. Let's see, where did I put the carrots?

Magician looks in empty pan and asks children if any of them are sitting on her carrots. Magician looks around.

Where are they? Oh wait, now I remember. I have to put the lid back on the pan, say the magic words Alacazam! Alacatarrots! Please put in the pan some carrots. And here they are!

The magician holds up a pan with some carrots now in it.

Now bunny can have some carrots! What did you all think of that trick? Clap your hands if you thought it was any good.

\section{Magician Performs Another Bag Trick}

My magic bag can do many tricks besides producing broccoli. Maybe know that it's warmed up it will work properly. Why don't I try to use my magic bag to tie a knot. Could my volunteer please come up here? Please look at this string. Now put it in the bag. Now look in the bag. Is there anything in the bag? No? Put the string in the bag. Magician lifts the bag up. Abracadabra! Alakazot! Bag, please tie me a knot! Okay, now reach into the bag and take out the yarn. See, now it has a knot? What did you think of that trick?

\section{$\underline{\text { Magician Performs the Coloring Book Trick }}$}

Look, I have this really cool book here. See, it has completely blank pages. But when I say Alakazar! Alakazines! Pages please fill in with lines, it becomes a coloring book!

Magician flips the pages showing line drawings. 
Wouldn't it be fun to fill in the coloring book? Unfortunately, we don't have time to do that this morning, so I'll have to borrow some colors from your clothes to color the drawings. Let me say the spell, Alakaza!, Alakazothes! Pages, please get some color from clothes.

Magician flips the pages showing colored line drawings.

So what did you think of that trick?

Magician Explains about Practicing

If some people knew how bad I was at doing these tricks, they might say, "Why don't you get a new job?" But, you know what? I've got everything I need to do magic. I've got the special white magic gloves, the special wand, a book of spells to say and I know how to do the tricks. I'm practicing my tricks and that's what's most important isn't it. If I practice some tricks, maybe I might become a better magician. What do you think? Can I be a better magician one day if I practice?

\section{$\underline{\text { Magician Performs Crayon Trick and Tells Secret }}$}

Well you were such a good audience I would like to show you one last trick. It's one of my favorites and if you all like, I will show you how this one is done. Its one you could do at home because you don't need special powers to do this trick. That's why it's my favorite. I'll take off my special gloves for this one.

I am going to put my crayons over here, and I will ask the helper to choose one crayon and put it in my hand. Make sure you show everyone else the color of the crayon first but make sure I don't see it. And put the crayon back in the jar. Okay now I will try and guess which one. This is a tough one, let me think. I know! It was the X crayon. Am I right?

This is a really easy trick. All you do is when you get the crayon in your hand is scratch a little off into your fingernail and then give it back. Look at your fingernail and see the color.

Magician shows children close up the crayon mark on finger.

I bet your family would love you to try it out on them. Let's try it again and you watch me scratch a bit with my fingernail this time. I'll sit closer to you this time so you can see me do it.

Magician repeats trick and then puts hand to mouth.

Oh, no! I forgot! Magicians aren't allowed to tell how tricks are done. Please don't tell other magicians that I told you how the trick was done because they might get mad at me. You see magicians are not supposed to tell the audience how to do the tricks. If everyone knew how to do the trick, there'd be no surprise. If other magicians find out I told you they might tell me that I'm not allowed to be a magician anymore and that would make me very sad. Can this be our secret? You won't tell any other magicians, will you? 


\section{Magician Turns Off Powers and Ends Show}

Well, that's the end of the magic show. Which trick did you like the best? Who thought the broccoli was the best trick? Who thought the carrot trick was the best trick? What about the coloring book trick? And who liked the crayon trick? Thank you so much for being my audience. I have had lots of fun doing the magic show for you, and I hope you've all had a good time too. Just remember, if you meet any other magicians, don't tell them that I told you about the crayon trick OK? I'd like you to line up at the door and I'll walk you back to the room.

But before I walk you back, I have to turn all my magic powers off. If I keep my magic powers on while I walk around the school I might do some magic by accident like turn a teacher into a frog. That would be terrible wouldn't it? So help me say the spell to turn my powers off. Alacazam! Alacapop! Turn my magic powers off. 


\section{Appendix E}

Cover Letter

\section{Dear Parent or Guardian,}

I would like to describe an upcoming project on children's cognitive development and memory abilities and obtain your permission for your child to participate. This study will help me understand how children's recall of events changes over the preschool years. If you allow your child to participate, he or she will watch a brief video about a birthday party, engage in cognitive skill activities, witness a live magic show, and answer questions about the events. All parts of the study will take place at your child's preschool. This study is described in greater detail in the following consent form.

If you have any questions, please feel free to contact Aryn C. Karpinski at (304) 293-2001 or via e-mail at akarpins@mix.wvu.edu.

Please return the signed consent form if you are willing to allow your child to participate. Thank you for considering allowing your child to participate in my study.

Sincerely,

Aryn C. Karpinski

Graduate Student - Department of Psychology

West Virginia University 
Appendix F

Consent Form

\section{PARENTAL or GUARDIAN CONSENT and INFORMATION FORM}

An Investigation of Theory of Mind, Rule

Understanding, and Event Memory in Preschoolers

\section{Introduction}

You, , have been asked to allow your child

to participate in this research study. This study is being conducted by Aryn C. Karpinski on behalf of Matthew H. Scullin, Ph.D., in the Department of Psychology at West Virginia University.

\section{Purposes of the Study}

The purpose of this study is to measure how preschoolers' verbal recall of events changes between the ages of 3 and 5 years. Another purpose of this study involves an investigation of how their recollections are related to preschool-age children's understanding of other people's knowledge (theory of mind) and their ability to understand and follow simple rules. The investigators are interested in both how much children can accurately remember about an event and the kinds of things that can cause errors in their recollections. It is sometimes valuable for a psychologist to be able to determine how well a child can describe an experienced event versus an event that the child did not experience, and the degree to which a child is accurate or suggestible when asked leading questions and given mild social pressure when asked about an event. The procedures and methods used in this study will add to the knowledge surrounding individual differences in event memory and suggestibility. Approximately 84 participants at all sites are expected to participate in this study. 
An Investigation of Theory of Mind, Rule Understanding, and Event Memory in Preschoolers

\section{Description of the Procedures}

The study will be performed at your child's preschool. Your child will participate in four different sessions. The first session will last 35-45 minutes. The second session will last 10-15 minutes. The third session will last 10-15 minutes. Lastly, the fourth session will last 35-45 minutes. These sessions will occur over the course of a month (session 1 in the first week, session 2 in the second week, session 3 in the third week, and session 4 in the fourth week). It is expected that these sessions will take place during non-instructional times. First, your child will watch a 5-minute video about a child's birthday party. Following the video, your child will participate in fun interaction with an experimenter, including some game-like activities that assess your child's ability to understand other people's points of view (for example, that a puppet may have a mistaken belief about where some mittens are located). Following these activities, your child will be interviewed about the birthday party video, starting with open-ended free recall questions followed by 18 probe questions about things that both did and did not happen in the video. Twice during the probe questions your child will be told that he or she made some mistakes (whether or not your child actually did so) and then half of the questions will be repeated. In the following week, your child will watch a magic show that will be performed in his or her classroom. A week after the show, your child will be asked a series of probe questions about things that did and did not happen in the show based upon information that the interviewer will incorrectly claim to have heard from your child's friends. Your child will also be asked a series of probe questions about an event that he or she did not witness or watch. In the last week, you child will participate in a number of activities with the experimenter that involve playing games that assess your child's ability to follow simple rules and rule changes (for example, your child will sort picture cards by color, then by shape).

At the conclusion of the interviews, your child will have the purpose of the study explained to him or her, be told that the interviewers sometimes asked about things that did not happen and sometimes incorrectly said the child had made a mistake, and receive a toy from a grab bag. Your child will be videotaped during the interviews in order to aid with their transcription. You have been given the opportunity to examine these questions and know that your child does not have to answer all the questions. Approximately 84 participants are expected to participate in this study ranging in age from 3 to 5 years.

\section{Risks or Discomforts}

There are no known or expected risks to your child from participating in this study, except for the mild frustration associated with answering the questions a second time after being told, sometimes falsely, that he or she has answered incorrectly.

Submission Date 08-31-05 Page 2 of 4

Initials Date




\section{An Investigation of Theory of Mind, Rule Understanding, and Event Memory in Preschoolers}

\section{$\underline{\text { Alternatives }}$}

You understand that your child does not have to participate in this study.

\section{$\underline{\text { Benefits }}$}

You understand that this study is not expected to be of direct benefit to your child, but the knowledge gained may be of benefit to others. Your child may receive a prize worth around $\$ 1$ from a grab bag upon completion of the interviews.

\section{Contact Persons}

For more information about this research, you can contact Aryn C. Karpinski at (304) 293-2001 or via e-mail at akarpins@mail.wvu.edu. Her advisor, Matthew H. Scullin, Ph.D., may be reached at (304) 293-2001 ext. 31676 or via e-mail at mhscullin@mail.wvu.edu. For more information regarding your child's rights as a research subject, you may contact the Executive Secretary of the Institutional Review Board at (304) 293-7073.

\section{Confidentiality}

You understand that any information about your child that is obtained as a result of participation in this research will be kept as confidential as legally possible. Your child's research records and test results, just like hospital records, may be subpoenaed by court order or may be inspected by federal regulatory authorities without your additional consent.

In addition, there are certain instances where the researcher is legally required to give information to the appropriate authorities. These would include mandatory reporting of infectious diseases, mandatory reporting of information about behavior that is imminently dangerous to your child such as suicide, child abuse, etc.

You understand that videotapes will be used to assist in the transcription of the interviews. These videotapes will be kept in a locked laboratory and once the interviews are transcribed, the tapes will be erased.

You are aware that in any publications that result from this research, neither your child's name nor any information from which your child might be identified will be published without your consent.

Submission Date 08-31-05 Page 3 of 4

Initials Date




\section{An Investigation of Theory of Mind, Rule Understanding, and Event Memory in Preschoolers}

\section{Voluntary Participation}

Participation in this study is voluntary. You or your child may refuse to participate in this study. You or your child may withdraw from this study at any time. Refusal to participate or withdrawal will not affect your child's future care, or your child's class standing or grades, and will involve no penalty to you or your child.

In the event new information becomes available that may affect your willingness to allow your child to participate in this study, this information will be given to you so that you can make an informed decision about whether or not to continue your child's participation. You have been given the opportunity to ask questions about the research, and have received answers concerning areas that you did not understand.

Upon signing this form, you will receive a copy.

I willingly consent to my child's participation in this research.

Signature of Parent or Guardian

Date

Time

Printed Name

Signature of Parent or Guardian

Date Time

Printed Name

Signature of Investigator or Investigator's Representative

Date Time

Printed Name

Submission Date 08-31-05

Page 4 of 4

Initials Date




\section{Aryn C. Karpinski}

\section{Curriculum Vitae}

\section{$\underline{\text { Professional Address }}$}

Department of Psychology

West Virginia University

53 Campus Drive

1124 Life Science Building

Morgantown, WV 26505-6040

Phone: (304) 685-1709

e-mail: Aryn.Karpinski@mail.wvu.edu arynkarp@hotmail.com

\section{Permanent Address}

4704 Queen Anne Ave.

Lorain, $\mathrm{OH} 44052$

Phone: (440) 282-4157

\section{EDUCATION}

West Virginia University

Program:

Degrees:

Advisors:
Life-Span Developmental Psychology

M.S. (April, 2006)

Ph.D. (Expected May, 2008)

Matthew H. Scullin, Ph.D.

Hawley Montgomery-Downs, Ph.D.
Miami University

Program:

Degree:

Advisor:
Oxford, OH

Psychology

B.A. (May, 2004)

Yvette Harris, Ph.D.

\section{RESEARCH INTERESTS}

\section{$\underline{\text { Cognition }}$}

Executive Function, Memory, Theory of Mind

\section{Children}

Preschoolers (ages 3 to 5 years)

\section{Sleep}

Sleep Disordered Breathing, Obstructive Sleep Apnea Syndrome, General Sleep Behavior and Problematic Sleep Behavior in Children 
SCHOLARSHIPS, HONORS, \& AWARDS

Thesis Milestone Award

Higher Education Resource Fund-(HERF)

Supplementary Fellowship

Honors in Psychology
WVU

WVU

MU
2005-2006

2004-2005

2004

\section{GRANTS AND OTHER FUNDING}

Sleep Research Society First-Time Travel Award 2006

Alumni Fund (Masters Thesis) 2005-2006

Psychology Alumni Travel Fund 2005-2006

Office of Academic Affairs and Research Travel Supplement 2005-2006

Eberly College of Arts and Sciences Travel Fund

2005-2006

\section{Professional AFFILIATIONS}

American Psychological Association Society for Research in Child Development The American Psychology and Law Society American Academy of Sleep Medicine/Sleep Research Society

\section{PROFESSIONAL EXPERIENCE}

Graduate Instructor:

Course:

Enrollment:

Duties:

Faculty Supervisor: Institution:

Graduate Instructor:

Course:

Enrollment:

Duties:

Faculty Supervisors:
August 2005 to Present

Psychology 241: Introduction to Human Development

60 Undergraduate Students (2 sections)

Primary instructor, lecture preparation, test

administration, records and grade maintenance

Matthew H. Scullin, Ph.D.

West Virginia University

August 2004 to August 2005

Psychology 101: Introduction to Psychology

120 Undergraduate Students (1 section)

Primary instructor, lecture preparation, test creation, test administration, records and grade maintenance

Jennifer Margrett, Ph.D.

Cheryl McNeil, Ph.D.

Katherine H. Karraker, Ph.D. 
Institution: $\quad$ West Virginia University

Research Assistant: $\quad$ August 2002 to May 2004

Laboratory Training: $\quad$ Social Psychology: Tacit Coordination

Faculty Supervisor: $\quad$ Garold Stasser, Ph.D.

Institution Miami University

\section{PUBLICATIONS}

\section{Unpublished}

Karpinski, A.C. (2004). Autism, Asperger's Syndrome, and High-Functioning Autism: A Review. Unpublished Honors Thesis, Miami University.

\section{$\underline{\text { In Progress }}$}

Karpinski, A.C., Scullin, M.H. (in progress) Theory of Mind and the Assessment of Suggestibility in Preschoolers.

\section{Presentations}

Karpinski, A.C., \& Patrick, J.H. (2005, November). Memory complaints: Mood and actual performance. Poster presented at the meeting of the Gerontological Society of America, Orlando, FL.

Karpinski, A.C., \& Scullin, M.H. (2006, April). Theory of Mind and the Assessment of Suggestibility. Poster presented at the meting of Sigma Xi, West Virginia University, Morgantown, WV.

\section{CONFERENCES}

Society for Research and Child Development

Gerontological Society of America

The American Psychology and Law Society

SLEEP
Atlanta, GA

$04 / 2005$

Orlando, FL

$11 / 2005$

St. Petersburg, FL 03/2006

Salt Lake City, UT 06/2006 


\section{REFERENCES}

Matthew H. Scullin, Ph.D.

Assistant Professor

Department of Psychology

West Virginia University

53 Campus Drive

1124 Life Sciences Building

Morgantown, WV 26505

Hawley Montgomery-Downs, Ph.D.

Assistant Professor

Department of Psychology

West Virginia University

53 Campus Drive

1124 Life Sciences Building

Morgantown, WV 26505

Yvette Harris, Ph.D.

Associate Professor

Department of Psychology

Miami University

114 Benton Hall

Oxford, $\mathrm{OH} 45056$ 